\title{
Políticas públicas para arranjos produtivos locais: análise comparativa dos arranjos de cerâmica de Monte Carmelo (MG), Porangatu (GO) e Itabaianinha (SE)
}

\author{
Juliene Barbosa Ferreira - UFU - juliene.ferreira@ ufu.br \\ Marisa Azevedo dos Reis Botelho - UFU - botelhomr@ufu.br
}

\begin{abstract}
Resumo
O resgate da importância do objeto local/regional por várias correntes teóricas tem impacto direto na visão e atuação de políticas públicas para promoção do desenvolvimento local, pois colocam em destaque os diferentes contextos econômicos, políticos e institucionais que conformam o ambiente no qual as empresa atuam. À luz dessa referência, o objetivo do presente trabalho é o de fazer uma análise comparativa do ambiente institucional e das políticas públicas que envolvem as empresas ceramistas e as instituições locais integradas aos arranjos produtivos (APLs) localizados em Monte Carmelo (MG), Porangatu (GO) e Itabaianinha (SE). A coleta de dados foi realizada no período de setembro de 2015 a janeiro de 2016, utilizando-se como instrumento o questionário elaborado pela Redesist. Foram entrevistadas um total de 93 empresas nos três APLs. Como resultados da pesquisa, identificou-se situações muito diferentes entre os três arranjos. Para o APL de Itabaianinha, identificou-se forte atuação do Estado, com o papel central da SEDETEC. Diferentemente, em Monte Carmelo a atuação de políticas públicas mostrou-se menos importante, sendo a estruturação e governança do APL exercida pela associação local de ceramistas. Ações de política pública também foram evidenciadas no APL de Porangatu, embora estejam ainda no campo das intenções, sem terem sido de fato implementadas.
\end{abstract}

Palavras chave: Arranjos Produtivos Locais; Indústria Cerâmica; Desenvolvimento Regional; Políticas Públicas.

\begin{abstract}
The importance of local/regional object by the various theoretical approachs has direct impact on vision and performance of public policies for promotion of local development, as they highlight the different economic, political and institutional contexts that shape the environment in which firms operate. Thus, the main objective of the paper is to make a comparative analysis of the institutional environment and public policies involving ceramic firms and local institutions integrated into the productive arrangements located in Monte Carmelo(MG), Porangatu (GO) and Itabaianinha (SE). Data collection was performed from September 2015 to January 2016, using as a tool the questionnaire drawn up by the Redesist. A sum of 93 companies were interviewed in the three LPAs. As results of the research, we identified very different situations among the three arrangements. For the Itabaianinha arrangement, a strong performance of the State was identified, with the central role of SEDETEC. In contrast, in Monte Carmelo the performance of public policies proved to be less important, with the structuring and governance of LPA exercised by the local association of ceramists. Public policy actions were also evidenced in Porangatu, although they are still in the field of intentions, without actually being implemented.
\end{abstract}

Key words: Local Productive Arrangements; Ceramic Industry; Regional Development; Public Policies. Classificação JEL: O18; L61; R11 


\section{Políticas públicas para arranjos produtivos locais: análise comparativa dos arranjos de cerâmica de Monte Carmelo (MG), Porangatu (GO) e Itabaianinha (SE)}

\section{Introdução}

A partir da década de 1970, intensificam-se os debates sobre aglomerações, bem como da importância das pequenas empresas no desenvolvimento econômico. Isso se deve, especialmente, ao êxito alcançado pelos distritos industriais italianos, fruto da reestruturação industrial observada a partir de 1975, cuja formação impulsionou o crescimento de várias províncias, levando ao que se chama, atualmente, Terceira Itália (BECATTINI, 1994). Desde então, o estudo do tema tem levado à utilização de uma gama de terminologias e conceitos para denominar o conjunto de empresas que se aglomeram em torno de determinadas atividades e em certas localidades..

Diante da diversidade de abordagens pertinentes ao tema, este trabalho submete-se à teoria da Economia da Inovação, que tem como principal referência os autores neoschumpeterianos. Optou-se por utilizar o conceito de APL estabelecido pela Rede de Pesquisa em Sistemas Produtivos e Inovativos Locais (RedeSist) que o designa como sendo um conjunto de instituições distintas que contribuem para o desenvolvimento e difusão de tecnologias, o qual é constituído por elementos (e relações entre elementos), quais sejam: organização interna das empresas, articulações entre elas e outras organizações, características sociais, econômicas e políticas do ambiente local, papel das agências e políticas públicas e privadas (CASSIOLATO, LASTRES, 2003b).

O resgate da importância do objeto local/regional pelas várias correntes teóricas tem impacto direto na visão e atuação de políticas públicas para promoção do desenvolvimento local, pois os APLs não vivem num limbo: estão inseridos num contexto econômico, político e institucional do qual as políticas públicas são um componente importante, mas não exclusivo. A literatura recente sobre APL destaca que "os arranjos produtivos locais surgem, frequentemente, de forma espontânea como supunha Marshall, mas seu desenvolvimento depende de ações deliberadas dos agentes envolvidos, que, além das firmas, incluem autoridades públicas e outras instituições provedoras de serviços”. Isto significa dizer que, o desenvolvimento posterior à geração do APL depende de uma ação conjunta e organizada, estabelecida por diversos mecanismos (ERBER, 2008, p.17). O trabalho de Lemos (1997) aponta que o papel do Estado é fundamental para a constituição de um arranjo exitoso. Neste sentido, o Estado, via políticas públicas atua, como promotor, indutor e, eventualmente, como estruturador do APL.

Assim, a pergunta que norteia o trabalho é: como as políticas públicas são implementadas e desenvolvidas nos arranjos produtivos locais de cerâmica vermelha localizados em Monte Carmelo, Porangatu e Itabaianinha? A partir disso, o objetivo geral proposto para este trabalho é o de fazer uma análise comparativa do ambiente institucional e das políticas públicas que envolvem as empresas ceramistas e as instituições locais integradas aos arranjos produtivos locais localizados em Monte Carmelo (MG), Porangatu (GO) e Itabaianinha (SE).

A justificativa para a proposta do objeto de estudo em questão está diretamente relacionada ao papel das micro e pequenas empresas, principalmente no tocante ao subsetor ceramista nas localidades propostas, pois apresentam representatividade econômica significativa. Em Sergipe, o subsetor de fabricação de produtos cerâmicos representa $6 \%$ das indústrias de transformação do estado. Em Goiás, esse subsetor representa 2,86\% e, em Minas Gerais, 1,94\%. Verifica-se que mais de $8 \%$ dos empregos gerados no estado de Sergipe são oriundos do subsetor de cerâmica vermelha. Em Goiás, é de 3,47\% e em Minas, de 2,86\%. A importância dos APLs para os seus territórios reside no seu papel na geração de emprego e renda para as suas respectivas regiões. No território onde se localiza o APL de Monte Carmelo (MG), mais de $40 \%$ do total das empresas são cerâmicas. Nos territórios que compõem os APLs de Itabaianinha (SE) e Porangatu (GO), as ceramistas representam mais de 50\% do total de empresas. Quanto a alguns municípios que compõem o APL de Itabaianinha, esse número é ainda mais expressivo, representando mais de $80 \%$ das empresas locais (PIA/IBGE, 2015). 
Para alcançar o objetivo proposto, fez-se uso do aporte teórico neoschumpeteriano vinculado ao conceito de APL para fundamentar a pesquisa de campo realizada e os resultados encontrados. Este trabalho se caracteriza por ser um estudo de caso. A coleta de dados foi realizada no período de setembro de 2015 a janeiro de 2016, utilizando-se como instrumento o questionário elaborado pela Redesist. O trabalho está estruturado em três seções além dessa introdução, sendo a primeira seção destinada a fazer um breve resumo sobre políticas públicas para APLs. A segunda seção faz uma caracterização do setor de cerâmica estrutural, apresentando alguns dados para o setor. A seção de número três tem por objetivo apresentar os resultados da pesquisa de campo e, por fim, as considerações finais.

\section{Políticas públicas para arranjos produtivos locais no Brasil}

Segundo Naretto, Botelho e Mendonça (2004), no Brasil, o esforço de estruturar políticas públicas para pequenas e médias empresas (PMEs) começou há 45 anos. No entanto, apenas no período recente, empresas desse porte passaram a receber atenção compatível com sua participação na economia nacional e com sua crescente importância nas estruturas produtivas modernas. As políticas públicas para PMEs envolvem a criação de instituições, normas tributárias específicas e instituições públicas de suporte ao sistema produtivo, como bancos oficiais, agências de fomento, institutos de pesquisa e universidades.

O quadro 1 apresenta de forma sucinta as principais ações e políticas públicas adotadas pelo governo federal, de 1960 a 2014, com o foco para o desenvolvimento de PMEs e, em especial, para os arranjos produtivos. O que se verifica são ações voltadas para o financiamento, no período de 1960 a 1970. A partir de 1972, surgem ações voltadas para o apoio à gestão empresarial das PMEs que se consolidam, de fato, na década de 1990 com a criação do SEBRAE e suas ações voltadas ao grupo das micro e pequenas empresas (MPEs).

Quadro 1 - Principais Políticas Nacionais para MPEs

\begin{tabular}{|c|c|c|}
\hline Período & Política Nacional & Objetivo \\
\hline 1960 & $\begin{array}{l}\text { Instituído o Grupo de Assistência à } \\
\text { Média e Pequena Empresa (GEAMPE). }\end{array}$ & Ampliar o suporte financeiro às MPEs. \\
\hline 1964 & $\begin{array}{l}\text { Grupo Executivo do Programa de } \\
\text { Financiamento à Pequena e Média } \\
\text { Empresa (Fipeme). }\end{array}$ & $\begin{array}{l}\text { Captação de recursos para financiamento de capital } \\
\text { fixo. }\end{array}$ \\
\hline 1966 & $\begin{array}{l}\text { Criação da Financiadora de Estudos e } \\
\text { Projetos (Finep), }\end{array}$ & $\begin{array}{l}\text { - Financiar o setor produtivo e laboratórios e centros } \\
\text { de pesquisa nas universidades. } \\
\text { - Gerenciar o Fundo Nacional de Desenvolvimento } \\
\text { Científico e Tecnológico (FNDCT). }\end{array}$ \\
\hline 1972 & $\begin{array}{l}\text { Criação do Centro Brasileiro de } \\
\text { Assistência Gerencial à Pequena e Média } \\
\text { Empresa (Cebrae) }\end{array}$ & $\begin{array}{l}\text { Difundir novas técnicas de gestão para as PMEs } \\
\text { a partir dos Centros de Apoio Gerencial (Ceags). }\end{array}$ \\
\hline 1984 & Aprovação do Estatuto da Microempresa. & $\begin{array}{l}\text { Tratamento diferenciado às microempresas, } \\
\text { nos campos administrativo, tributário, previdenciário, } \\
\text { trabalhista, creditício e de desenvolvimento } \\
\text { empresarial. }\end{array}$ \\
\hline 1988 & Constituição & $\begin{array}{l}\text { Estabelecer tratamento jurídico, administrativo, } \\
\text { tributário e creditício favorecido às empresas de } \\
\text { pequeno porte. }\end{array}$ \\
\hline $\begin{array}{l}1990- \\
1992\end{array}$ & $\begin{array}{l}\text { Criação do Serviço Brasileiro de Apoio } \\
\text { às Micro e Pequenas Empresas (Sebrae) e } \\
\text { do MCT. }\end{array}$ & $\begin{array}{l}\text { Por em prática o estabelecido pela Constituição } \\
\text { (1988) e pela microempresa. }\end{array}$ \\
\hline 1996 & $\begin{array}{l}\text { Criação do Sistema Integrado de } \\
\text { Pagamento de Impostos e Contribuições } \\
\text { das Microempresas e Empresas de } \\
\text { Pequeno Porte (Simples). }\end{array}$ & $\begin{array}{l}\text { Introduziu o sistema simplificado de pagamento de } \\
\text { impostos e definiu novas regras de enquadramento } \\
\text { tributário das PMEs. }\end{array}$ \\
\hline 1991 & $\begin{array}{l}\text { Criação do Consórcio de Capitalização de } \\
\text { Empresas de Base Tecnológica (Contec). }\end{array}$ & $\begin{array}{l}\text { Estimular o surgimento de PMEs em atividades de } \\
\text { inovação tecnológica. }\end{array}$ \\
\hline 1999 & Criação de Fundos Setoriais. & $\begin{array}{l}\text { Fomentar o desenvolvimento de arranjos produtivos } \\
\text { locais, projetos regionais de inovação, incubadoras de }\end{array}$ \\
\hline
\end{tabular}




\begin{tabular}{|c|c|c|}
\hline & & empresas e parques tecnológicos. \\
\hline 2000 & $\begin{array}{l}\text { Programa de Apoio Tecnológico à } \\
\text { Exportação (Progex). }\end{array}$ & $\begin{array}{l}\text { Financiar a adaptação tecnológica dos produtos das } \\
\text { MPEs para atendimento às exigências de mercados } \\
\text { externos. }\end{array}$ \\
\hline $\begin{array}{l}2004- \\
2007\end{array}$ & $\begin{array}{l}\text { Plano Plurianual Política Industrial, } \\
\text { Tecnológica e de Comércio Exterior } \\
\text { (Pitce). }\end{array}$ & $\begin{array}{l}\text { Propõem estratégias de promoção do desenvolvimento } \\
\text { econômico, social e regional como foco nas MPEs e } \\
\text { nos APL. }\end{array}$ \\
\hline 2004 & $\begin{array}{l}\text { Criação de mecanismos de financiamento } \\
\text { às MPEs pelo BNDES. }\end{array}$ & $\begin{array}{l}\text { Oferecer mecanismos de financiamento à MPEs: } \\
\text { Modermaq; Modercarga; Novo Prosoft; Profarma. }\end{array}$ \\
\hline $\begin{array}{l}2011- \\
2014\end{array}$ & $\begin{array}{l}\text { Plano Nacional de Empreendedorismo - } \\
\text { Plano Brasil Maior }\end{array}$ & $\begin{array}{l}\text { Mobilizar as forças produtivas para inovar, competir } \\
\text { e crescer, dinamizando as competências presentes nas } \\
\text { empresas, na academia e na sociedade. }\end{array}$ \\
\hline
\end{tabular}

Fonte: Elaboração própria com base em Naretto, Botelho e Mendonça (2004) e Brasil (2013).

As políticas voltadas para APLs são ainda mais recentes. Refletindo tendência internacional no sentido de reconhecer a necessidade de desenvolver uma abordagem sistêmica para a promoção da inovação e da competitividade das empresas e dos agentes individuais, observa-se, na década de 2000, o desenvolvimento de políticas direcionadas a grupos de empresas. Em particular, as políticas para promover o desenvolvimento tecnológico e industrial têm reconhecido que a aglomeração de empresas e o melhor aproveitamento das vantagens coletivas geradas por suas interações, pode contribuir para constituição de vantagens competitivas sustentáveis (CASSIOLATO, LASTRES., 2003a).

Embora se reconheça a necessidade de política e apoio do Estado para a promoção dos APLs, as políticas tem sido implementadas de forma fragmentada, utilizando-se de critérios de escolha de APLs específicos ou de setores determinados. A prática das políticas com foco em APLs, por parte de diferentes organizações no nível federal, estadual e municipal, revela uma gama variada de critérios de seleção dos casos a serem apoiados. Estes podem ser resumidos como apresentados no quadro 2.

Quadro 2. Critérios de seleção de APLs para politicas públicas

\begin{tabular}{|l|l|}
\hline \multicolumn{1}{|c|}{ Recorte } & \multicolumn{1}{c|}{ Objetivo das ações } \\
\hline $\begin{array}{l}\text { Tipo/classe } \\
\text { atividade }\end{array}$ de & $\begin{array}{l}\text { Ações de apoio têm se direcionado prioritariamente para segmentos da indústria de } \\
\text { transformação, com ênfase em atividades consideradas "tradicionais". Também têm recebido } \\
\text { destaque as atividades agroindustriais de pequena escala. }\end{array}$ \\
\hline Foco no setor & $\begin{array}{l}\text { Muitas experiências estaduais apontam para APLs que abrangem toda a estrutura produtiva } \\
\text { de um dado setor de atividade no estado. Isto constitui, de fato, uma nova roupagem para a } \\
\text { política setorial sem base territorial específica. }\end{array}$ \\
\hline $\begin{array}{l}\text { Unidades } \\
\text { administrativas }\end{array}$ & $\begin{array}{l}\text { Observam-se recortes de APLs por municípios e estados, favorecendo a ponta das cadeias } \\
\text { produtivas e desarticulando estruturas produtivas. }\end{array}$ \\
\hline $\begin{array}{l}\text { Caracterização por } \\
\text { critérios institucionais }\end{array}$ & $\begin{array}{l}\text { Diferentes instituições têm adotado critérios mais condizentes com sua experiência de } \\
\text { atuação, caracterizando como APLs os casos: centrados em MPE, que já alcançaram um } \\
\text { dado grau de desenvolvimento; ou que possuem estruturas de governança bem estabelecidas. }\end{array}$ \\
\hline Objetivos de política & $\begin{array}{l}\text { De acordo com o objetivo e missão de cada instituição, têm sido priorizados APLs que } \\
\text { constituam um meio para: geração de emprego e renda; desenvolvimento local; inovação em } \\
\text { áreas intensivas em conhecimento. }\end{array}$ \\
\hline
\end{tabular}

Fonte: Adaptado de MATOS (2011, p. 26).

Outra forma de aplicação e atuação de políticas públicas para APLs é estabelecida no documento elaborado pelo MDIC sobre políticas para APLs, o qual aponta cinco eixos estruturantes para o foco de atuação das políticas públicas (BRASIL/MDIC, 2006a, p. 13):

- Crédito e Financiamento, a fim de suportar o processo de especialização produtiva localizada;

- Governança e Cooperação, para consolidar as relações inter firmas;

- Tecnologia e Inovação, para promoção da capacidade tecnológica endógena;

- Formação e Capacitação, na construção de capital humano diferenciado nos APLs, e

- Acesso aos Mercados Nacional e Internacional, para sustentabilidade do arranjo produtivo.

Nesta direção, o trabalho de Costa (2007) propõe classificar os aglomerados com base em critérios capazes de fornecer linhas gerais de intervenção do Estado por meio de políticas públicas. Sugere-se os seguintes objetivos de política (COSTA, 2007): 
a) aumentar o grau de cooperação e coordenação nas atividades dos agentes do aglomerado;

b) fomentar o desenvolvimento das empresas e consequentemente do aglomerado;

c) fomentar o desenvolvimento local e regional;

d) fomentar a exportação e a colocação dos produtos do aglomerado em novos mercados;

e) fomentar o desenvolvimento tecnológico, observando o grau de tecnologia incorporada no produto ou no processo produtivo;

f) fomentar o estabelecimento de instituições de ensino e pesquisa;

g) melhorar a qualidade do produto e dos processos produtivos;

h) aumentar o nível de formalização das empresas;

i) aumentar o nível de formalização da mão de obra;

j) aumentar o índice de sobrevivência das empresas.

Assim, para o debate sobre as alternativas possíveis para reorientação das políticas para APLs nos estados, de modo a ampliar seu alcance e efetividade, devem-se considerar as características e limitações do aparato institucional que dá suporte a esse tipo de política. Essa análise contempla uma ampla gama de aspectos, dentre os quais, destacam-se (quadro 3):

Quadro3. Fatores para orientação de política pública

\begin{tabular}{|c|l|}
\hline \multicolumn{1}{|c|}{ Fator } & \multicolumn{1}{c|}{ Conteúdo } \\
\hline Articulação & $\begin{array}{l}\text { a forma de articulação entre os diferentes órgãos que atuam no apoio a APLs nos estados, e destes } \\
\text { com os núcleos estaduais de coordenação dessas políticas (NE-APLs, Rede APL etc.); }\end{array}$ \\
\hline Autonomia & $\begin{array}{l}\text { o grau de autonomia dos estados no processo de formulação e implementação de políticas. Em outras } \\
\text { palavras, busca-se explicitar até que ponto as ações adotadas são induzidas a partir de orientações de } \\
\text { âmbito federal (GTP-APL, MCT, MDIC etc.) ou derivam do desdobramento das políticas de } \\
\text { desenvolvimento no âmbito do estado; }\end{array}$ \\
\hline Formalização & $\begin{array}{l}\text { o grau de formalização das políticas, em termos da existência de um aparato legal para definição das } \\
\text { mesmas como programas de ação dos governos estaduais e, dada sua formalização, as condiçes de } \\
\text { operacionalização dessas políticas em termos da disponibilidade de recursos orçamentários, } \\
\text { qualificação de gestores etc.; }\end{array}$ \\
\hline Continuidade & $\begin{array}{l}\text { o caráter contínuo ou descontínuo das mesmas e sua inserção nas estratégias de desenvolvimento em } \\
\text { âmbito estadual. }\end{array}$ \\
\hline
\end{tabular}

Fonte: adapatado de CAMPOS, VARGAS, STALLIVIERI (2010).

Verifica-se que cada um dos documentos apresentados anteriormente expõe uma visão a respeito dos objetivos de políticas públicas para a promoção dos arranjos, os quais não são excludentes, mas complementares. Visto sob outra ótica, alguns são mais específicos e pontuais, como o documento do MDIC (2006), enquanto outros são mais abrangentes e genéricos, como o de Matos (2011). Enfim, podese concluir, com as diversas abordagens apresentadas, que há várias perspectivas de enxergar a política, o que implica em alternativas e possibilidades para classificar os arranjos a partir de objetivos de intervenção. "Não há assim, uma fórmula única" (TATSCH, BOTELHO, 2013 p. 19).

Além do foco de atuação das políticas públicas, outro fator importante a ser observado diz respeito ao aparato institucional. Conforme o Relatório de Políticas Públicas elaborado pelo BNDES (2010), o aparato institucional da política para APLs apresenta uma elevada diversidade nos formatos organizacionais, nas formas de articulação, nos graus de autonomia e nos instrumentos que conformam esse aparato de apoio aos arranjos e sistemas produtivos locais identificados nos estados. Tal diversidade revela a riqueza das experiências estaduais no tocante à política de apoio aos APLs, além de demonstrar que não existe um modelo geral aplicável a todos os casos.

A partir do pressuposto de que existe uma gama de possibilidades de atuação do Estado para os APLs, e quão importante para o desenvolvimento destes é essa interferência, a seção 3 dedicar-se-á à descrição e análise das políticas públicas voltadas aos três arranjos selecionados. Antes, a próxima seção tem por objetivo caracterizar o setor de cerâmica vermelha para o Brasil, demonstrar a importância econômica do setor e caracterizar os APLs a serem analisados. 


\section{Breve caracterização do setor de cerâmica estrutural e dos APLs selecionados}

O setor de cerâmica vermelha, que se caracteriza, principalmente, pela produção de telhas e tijolos, não é um setor intenso em exportação, se comparado a outros setores do próprio segmento de minerais não metálicos, como cerâmica de revestimento, cimento, caulim, entre outros.

A Tabela 1 compara a produção da indústria da cerâmica vermelha de telhas e tijolos com a produção de telhas e blocos de cimento. Embora os dados não nos permitam uma comparação precisa em termos de valor absoluto, em função das diferenças de unidades de medidas, é possível verificar que o segmento de telhas de cerâmica mantém um crescimento ao longo do período, apresentando uma variação de 134\% de 2008 para 2014, enquanto o segmento de telhas de cimento apresenta um crescimento ainda mais expressivo, na ordem de $1.161 \%$ de 2008 para 2014. Não é possível afirmar que o setor de cerâmica tenha perdido mercado, mas é possível verificar que o setor de produtos de cimento (telhas e blocos) para construção aumenta sua participação no mercado, porém não em detrimento da perda de mercado do setor cerâmico.

O segmento que perde mercado é o de telha de fibrocimento com amianto crisotila (popularmente conhecida como telha Eternit, em função de ter sido a marca de maior circulação no mercado até a década de 2000).

Tabela 1. Produção Brasileira de Telhas, Blocos e Tijolos (Cimento e Cerâmica)

\begin{tabular}{lccccccc}
\hline & $\mathbf{2 0 0 8}$ & $\mathbf{2 0 0 9}$ & $\mathbf{2 0 1 0}$ & $\mathbf{2 0 1 1}$ & $\mathbf{2 0 1 2}$ & $\mathbf{2 0 1 3}$ & $\mathbf{2 0 1 4}$ \\
\hline $\begin{array}{l}\text { Blocos e tijolos de cimento } \\
\text { ou concreto (Ton) }\end{array}$ & 1.776 .795 & 1.549 .633 & 1.760 .009 & 3.386 .673 & 3.412 .694 & 3.039 .956 & 3.741 .045 \\
$\begin{array}{l}\text { Telhas de cimento ou } \\
\text { concreto (Ton) }\end{array}$ & 339.449 & 444.492 & 482.569 & 937.173 & 1.151 .819 & 3.160 .004 & 3.940 .141 \\
$\begin{array}{l}\text { Telhas de cerâmica (Mil } \\
\text { unidades) }\end{array}$ & 2.219 .051 & 2.312 .689 & 2.416 .587 & 2.620 .546 & 2.429 .733 & 2.291 .439 & 2.987 .696 \\
$\begin{array}{l}\text { Tijolos perfurados de } \\
\text { cerâmica (Mil unidades) }\end{array}$ & 4.676 .731 & 4.479 .532 & 5.072 .199 & 5.304 .855 & 5.968 .811 & 6.860 .164 & 9.298 .310 \\
\hline
\end{tabular}

Fonte: IBGE - Pesquisa Industrial Anual - Produto.

É possível verificar na tabela 2 que, o subsetor de cerâmica vermelha (CNAE - 23.4) representa $2,81 \%$ do número de empresas da indústria de transformação do Brasil. Analisando-se a participação do subsetor de cerâmica no total das empresas da indústria de transformação por Estado, verifica-se que, em Sergipe, é de 20,2,3\%, sendo essa a maior participação dos estados brasileiros analisados. Minas Gerais apresenta a menor participação, com 10,78\%. Esses dados mostram a importância do subsetor de cerâmica vermelha, o qual é expressivo nos três estados em questão. A participação das empresas ceramistas no setor de minerais não metálicos, por estado, é de: 21,88\% em Minas Gerais; 54,51\% em Goiás; e 67,77\% no Estado de Sergipe.

A importância do setor para o desenvolvimento da região pode ser expresso com dados de geração de empregos no setor para a região, conforme Tabela 3, que mostra o número de empregados com vínculo empregatício na indústria de transformação no setor de minerais não metálicos e no setor de fabricação de produtos cerâmicos. O número de empregos para o subsetor de fabricação de produtos cerâmicos representa 52,37\% da mão de obra que compõe o setor de minerais não metálicos no Estado de Sergipe, 33,51\%, em Goiás; e 22,78\%, em Minas Gerais. Em Goiás, esse dado pode ser explicado pela expansão e desenvolvimento do setor de pedras preciosas (com dois APLs bem estruturados no estado), bem como do setor de fabricação de produtos de cerâmica refratários (dois APLs) (REDE APL MINERAL, 2015). 
Tabela 2. Número de Empresas no Subsetor Cerâmico (CNAE 2.0) $)^{1}$ e sua Participação no Estado.

\begin{tabular}{|c|c|c|c|c|c|c|c|c|c|}
\hline $\begin{array}{l}\text { Unidades da } \\
\text { Federação }\end{array}$ & $\begin{array}{c}\text { CNAE } \\
2.0\end{array}$ & 2008 & 2009 & 2010 & 2011 & 2012 & 2013 & 2014 & $\begin{array}{c}\text { Participação } \\
\text { no setor }(\%) \\
2014\end{array}$ \\
\hline \multirow{3}{*}{ Brasil } & $\mathrm{C}$ & 177.979 & 181.332 & 185.299 & 194.337 & 188.033 & 198.810 & 203.927 & \multirow[b]{3}{*}{$2,81 \% *$} \\
\hline & 23 & 14.437 & 14.578 & 15.690 & 16.839 & 17.282 & 18.392 & 18.860 & \\
\hline & 23.4 & 4.803 & 4.885 & 5.075 & 5.223 & 5.336 & 5.495 & 5.736 & \\
\hline \multirow{3}{*}{ Minas Gerais } & $\mathrm{C}$ & 21.430 & 21.948 & 22.904 & 23.394 & 22.468 & 23.433 & 23.654 & \multirow{3}{*}{$\begin{array}{l}10,78 \% * * \\
23,88 \% * * *\end{array}$} \\
\hline & 23 & 2.057 & 2.005 & 2.182 & 2.406 & 2.409 & 2.524 & 2.550 & \\
\hline & 23.4 & 471 & 523 & 574 & 539 & 575 & 610 & 609 & \\
\hline \multirow{3}{*}{ Goiás } & $\mathrm{C}$ & 5.287 & 5.786 & 5.939 & 6.346 & 6.307 & 7.057 & 6.883 & \multirow{3}{*}{$\begin{array}{l}10,79 \% * * \\
54,51 \% * * *\end{array}$} \\
\hline & 23 & 476 & 568 & 616 & 740 & 720 & 795 & 743 & \\
\hline & 23.4 & 134 & 158 & 223 & 289 & 342 & 387 & 405 & \\
\hline \multirow{3}{*}{ Sergipe } & $\mathrm{C}$ & 831 & 865 & 850 & 1.011 & 907 & 1.080 & 1.043 & \multirow{3}{*}{$\begin{array}{l}20,23 \% * * \\
67,77 \% * * *\end{array}$} \\
\hline & 23 & 145 & 138 & 158 & 188 & 170 & 178 & 211 & \\
\hline & 23.4 & 89 & 95 & 102 & 118 & 125 & 132 & 143 & \\
\hline
\end{tabular}

Fonte: IBGE - Pesquisa Industrial Anual - Empresa, 2016.

Nota: * Participação do subsetor de fabricação de produtos cerâmicos no total da indústria de transformação no Brasil, para o ano de 2014.

** Participação do subsetor de fabricação de produtos cerâmicos no total do setor de minerais não metálicos, por Estado, para o ano de 2014.

*** Participação do subsetor de Fabricação de Produtos Cerâmicos no total da indústria de transformação, por Estado, para o ano de 2014.

Analisando-se especificamente o setor de fabricação de produtos cerâmicos, veririfca-se que o número de empregos com vínculos empregatícios aumentou no período de 2009 para 2015 na razão de 2,52\% em Minas Gerais, 7,02\%, em Goiás, e 28,94\%, em Sergipe.

Tabela 3. Número de Empregos com Vínculo Empregatício - 2009-2015.

\begin{tabular}{|c|c|c|c|c|c|c|c|c|c|}
\hline & & 2015 & 2014 & 2013 & 2012 & 2011 & 2010 & 2009 & $\begin{array}{c}\text { Participação } \\
\%\end{array}$ \\
\hline \multirow{3}{*}{$\begin{array}{l}\text { Minas } \\
\text { Gerais }\end{array}$} & Indústria de transformação & 768.036 & 838.813 & 851.867 & 841.694 & 831.949 & 808.188 & 750.241 & \\
\hline & Prod. Mineral Não Metálico & 52.812 & 57.008 & 56.503 & 54.618 & 53.435 & 50.343 & 45.100 & $1,55 *$ \\
\hline & $\begin{array}{l}\text { Fabricação de artefatos de } \\
\text { cerâmica }\end{array}$ & 11.545 & 12.985 & 13.268 & 13.259 & 13.146 & 12.151 & 11.261 & $22,78 * *$ \\
\hline \multirow{3}{*}{ Goiás } & Indústria de transformação & 238.040 & 251.031 & 248.639 & 236.483 & 224.316 & 204.593 & 188.356 & \\
\hline & Prod. Mineral Não Metálico & 13.601 & 14.690 & 14.748 & 14.576 & 14.508 & 12.752 & 10.857 & $1,96 *$ \\
\hline & $\begin{array}{l}\text { Fabricação de artefatos de } \\
\text { cerâmica }\end{array}$ & 4.602 & 4.922 & 5.098 & 5.361 & 5.480 & 5.146 & 4.300 & $33,51 * *$ \\
\hline \multirow{3}{*}{ Sergipe } & Indústria de transformação & 48.173 & 48.306 & 47.161 & 46.653 & 44.792 & 41.477 & 36.353 & \\
\hline & Prod. Mineral Não Metálico & 5.726 & 6.284 & 6.409 & 6.263 & 5.516 & 4.444 & 4.593 & $13,01 *$ \\
\hline & $\begin{array}{l}\text { Fabricação de artefatos de } \\
\text { cerâmica }\end{array}$ & 2.865 & 3.291 & 3.315 & 3.322 & 2.958 & 2.312 & 2.222 & $52,37 * *$ \\
\hline
\end{tabular}

Fonte: RAIS, 2016.

Verifica-se que, nacionalmente, o setor de minerais não metálicos e o subsetor de fabricação de produtos cerâmicos são importantes e, atualmente, esses têm se configurado como opções de desenvolvimento regional, com ações de políticas públicas. Segundo o Anuário Estatistico do Setor de

1 CNAE 2.0: $\quad$ C- Indústria de transformação; 23 - Fabricação de produtos minerais não metálicos e 23.4 - Fabricação de produtos cerâmicos para uso na construção civil (exclui os produtos refratários, louças e azulejos). 
Minerais Não Metálicos (2015), os principais polos de produção industrial de cerâmica vermelha no país têm sua estrutura produtiva organizada na forma de Arranjos Produtivos Locais (APL).

Até aqui, o objetivo foi apresentar o setor de minerais não metálicos, em especial, o de fabricação de produtos cerâmicos para o Brasil e para os Estados nos quais os APLs estudados estão localizados. Faz-se necessário, agora, caracterizar cada APL. O quadro 4 apresenta as principais características dos APLs que foram investigados.

Quadro 4. Características dos APLs estudados

\begin{tabular}{|l|l|l|l|l|}
\hline \multicolumn{1}{|c|}{ APL } & Localização & $\begin{array}{l}\text { No empresas } \\
\text { entrevistadas }\end{array}$ & \multicolumn{1}{|c|}{$\begin{array}{c}\text { Formalização } \\
\text { Apoio institucional } \\
\text { público }\end{array}$} \\
\hline Itabaianinha & Sergipe & 30 & $\begin{array}{l}\text { Formalizado em 2007 por } \\
\text { determinação do governo do Estado } \\
\text { por intermédio da Secretaria de } \\
\text { Desenvolvimento (SEDETEC). }\end{array}$ & $\begin{array}{l}\text { SEDETEC } \\
\text { IEL } \\
\text { SEBRAE }\end{array}$ \\
\hline $\begin{array}{l}\text { Monte } \\
\text { Carmelo }\end{array}$ & $\begin{array}{l}\text { Minas } \\
\text { Gerais }\end{array}$ & 28 & $\begin{array}{l}\text { Formalizado em 2004 por iniciativa } \\
\text { da governança do arranjo. }\end{array}$ & $\begin{array}{l}\text { Associação ceramistas (ACEMC) } \\
\text { Faculdade (FUCAMP) } \\
\text { Laboratório de Ensaios } \\
\text { (LEMC) }\end{array}$ \\
\hline Porangatu & Goiás & 35 & $\begin{array}{l}\text { Formalizado em 2007 por iniciativa } \\
\text { da governança do arranjo. }\end{array}$ & $\begin{array}{l}\text { Associação ceramistas (ASCENO) } \\
\text { Secretaria } \\
\text { Desenvolvimento } \\
\text { SEBRAE }\end{array}$ \\
\hline
\end{tabular}

Fonte: Elaboração própria com base na pesquisa de campo

Apresentada a importância do setor e as características dos APLs, a próxima seção se destina a apresentar o resultado da pesquisa de campo realizada nos três APLs, com o intuito de descrever e avaliar as principais ações de política pública implementadas em cada APL.

\section{Políticas públicas para os APLs de Cerâmica Vermelha em Monte Carmelo, Porangatu e Itabaianinha}

A presente seção tem como objetivo descrever o resultado da pesquisa de campo em relação à implementação e adoção de políticas públicas nos APLs estudados. Foram realizadas entrevistas com 93 empresas, sendo 36 empresas em Itabaianinha, 35 em Porangatu e 28 em Monte Carmelo. As entrevistas foram realizadaa no período de setembro de 2015 a janeiro de 2016, utilizando-se como instrumento o questionário elaborado pela Redesist ${ }^{2}$. No mesmo período foram entrevistadas diversas instituições de apoio e de representação nos referidos APLs que, embora não estejam discriminadas no trabalho por razões de espaço, contribuíram para a análise efetuada nesta seção.

Verificou-se, na pesquisa de campo, que a forma como cada Estado aplica as políticas relaciona-se com os objetivos a serem atingidos por ela e com a visão que se adota para os aglomerados (TATSCH, BOTELHO, 2013). Vale ressaltar, portanto, que, nos três arranjos aqui mencionados, as ações de apoio têm sido realizadas, embora com aparato institucionais diversos, como apresentaremos a seguir.

Para o APL de Monte Carmelo, a pesquisa de campo revela que algumas ações de políticas voltadas para a promoção de APLs de cerâmica estrutural (vermelha) são de conhecimento da maioria das empresas localizados no APL e afirmam que participam de tais políticas, conforme tabela 4. Os dados mostram um entendimento de política pública, por parte do empresários, muito peculiar à forma de governança do arranjo. Verifica-se que $100 \%$ das micro empresas afirmam que conhecem alguma forma de política pública especifica para o setor, e que 66,7\% afirmam que participam da política citada. No caso das pequenas empresas, $90 \%$ afirmam que conhecem e $41,5 \%$ participam. Para as médias e grandes

\footnotetext{
${ }^{2}$ Rede de Pesquisas em Sistemas e Arranjos Produtivos e Inovativos, localizada no Instituto de Economia da Universidade Federal do Rio de Janeiro. O questionário foi formulado com base no aporte teórico neoschumpeteriano.
} 
empresas esse índice diminui, sendo que $75 \%$ das médias empresas afirmam conhecer as políticas e $50 \%$ participam, e para as grandes empresas, de forma surpreendente, tem-se que $50 \%$ não conhece e os outros $50 \%$ conhece, embora delas não participem.

Quando questionados acerca da política a qual se referiam, os gestores das micro e pequenas empresas foram categóricos ao delinear as políticas adotadas pelo APL para melhoria de qualidade, implementando certificação de qualidade junto ao INMETRO e o Programa Setorial de Qualidade (PSQ). O que contraria as MPEs relaciona-se ao fato do governo federal não disponibilizar instrumentos ou meios que possibilite às empresas a promovê-los.

Os gestores das médias empresas foram unânimes ao afirmarem que também fazem parte desses programas de certificação e do PSQ. Entretanto, quase $60 \%$ deles não entendem que seja uma política específica para o setor. Quanto às grandes empresas, embora sejam apenas duas no arranjo, um gestor afirma que conhece, porém não participa, enquanto o outro afirma não conhecer alguma política federal específica para o setor. Quando questionados sobre os programas de certificação e qualidade, os gestores informaram que não reconhecem como sendo uma política específica do setor de cerâmica vermelha. $\mathrm{O}$ PSQ para o setor cerâmico é um adendo do Programa Brasileiro da Qualidade e Produtividade do Habitat (PBQP-H).

O caso do APL de Porangatu se distingue do de Monte Carmelo, principalmente, no que diz respeito ao aparato institucional de apoio e adesão às políticas públicas. O APL é formalizado, está cadastrado na base de dados da Rede APL Mineral e faz parte do grupo de APLs escolhidos pela Rede Goiana de APL do governo estadual de Goiás. Entretanto, $100 \%$ das empresas afirmam que não conhecem as ações promovidas pelos municípios. Com relação às ações de cunho nacional, promovidas pelo governo federal, $100 \%$ das grandes empresas, mais de $55 \%$ das médias, $40 \%$ das pequenas e apenas $11,1 \%$ das micro afirmam conhecer e participar dessas ações.

Tabela 4. Nível de conhecimento das Políticas especificas para o setor das empresas dos APLs - (número expresso em percentual das empresas).

\begin{tabular}{|c|c|c|c|c|c|c|c|c|c|c|c|c|c|}
\hline & \multirow[b]{2}{*}{ Instituição } & \multicolumn{3}{|c|}{ Micro } & \multicolumn{3}{|c|}{ Pequena } & \multicolumn{3}{|c|}{ Média } & \multicolumn{3}{|c|}{ Grande } \\
\hline & & $\begin{array}{c}\text { Não } \\
\text { conhece }\end{array}$ & $\begin{array}{c}\text { Conhece, } \\
\text { mas não } \\
\text { participa }\end{array}$ & $\begin{array}{c}\text { Conhece } \\
\mathrm{e} \\
\text { participa }\end{array}$ & $\begin{array}{c}\text { Não } \\
\text { conhece }\end{array}$ & $\begin{array}{l}\text { Conhece, } \\
\text { mas não } \\
\text { participa }\end{array}$ & $\begin{array}{c}\text { Conhece } \\
\mathrm{e} \\
\text { participa }\end{array}$ & $\begin{array}{c}\text { Não } \\
\text { conhece }\end{array}$ & $\begin{array}{c}\text { Conhece, } \\
\text { mas não } \\
\text { participa }\end{array}$ & $\begin{array}{c}\text { Conhece } \\
\text { e } \\
\text { participa }\end{array}$ & $\begin{array}{c}\text { Não } \\
\text { conhece }\end{array}$ & $\begin{array}{l}\text { Conhece, } \\
\text { mas não } \\
\text { participa }\end{array}$ & $\begin{array}{c}\text { Conhece } \\
\mathrm{e} \\
\text { participa }\end{array}$ \\
\hline \multirow{8}{*}{ 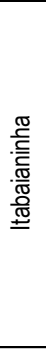 } & 1. Governo & & & & & & & & & & & & \\
\hline & Federal & 16,7 & 50,0 & 33,3 & 5,9 & 35,3 & 58,8 & 33,3 & 50,0 & 16,7 & 0,0 & 0,0 & 100,0 \\
\hline & 2. Governo & & & & & & & & & & & & \\
\hline & Estadual & 2,0 & 5,9 & 93,1 & 11,7 & 20,0 & 67,3 & 2,0 & 11,5 & 87,5 & 0,0 & 0,0 & 100,0 \\
\hline & 3. Goevrno Local & & & & & & & & & & & & \\
\hline & Municipal & 100,0 & 0,0 & 0,0 & 100,0 & 0,0 & 0,0 & 100,0 & 0,0 & 0,0 & 100,0 & 0,0 & 0,0 \\
\hline & 4. SEBRAE & 0,0 & 50,0 & 50,0 & 11,8 & 23,5 & 64,7 & 0,0 & 33,3 & 66,7 & 0,0 & 100,0 & 0,0 \\
\hline & $\begin{array}{l}\text { 5. Outras } \\
\text { Instituições }\end{array}$ & 50,0 & 50,0 & 0,0 & 23,5 & 70,6 & 5,9 & 33,3 & 50,0 & 16,7 & 0,0 & 100,0 & 0,0 \\
\hline \multirow{5}{*}{ 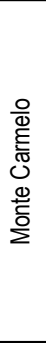 } & $\begin{array}{l}\text { 1. Governo } \\
\text { Federal }\end{array}$ & 0,0 & 33,3 & 66,7 & 8,3 & 50,0 & 41,7 & 25,0 & 25,0 & 50,0 & 50,0 & 50,0 & 0,0 \\
\hline & $\begin{array}{l}\text { 2. Governo } \\
\text { Estadual }\end{array}$ & 100,0 & 0,0 & 0,0 & 100,0 & 0,0 & 0,0 & 100,0 & 0,0 & 0,0 & 100,0 & 0,0 & 0,0 \\
\hline & $\begin{array}{l}\text { 3. Goevrno Local } \\
\text { Municipal }\end{array}$ & 100,0 & 0,0 & 0,0 & 100,0 & 0,0 & 0,0 & 100,0 & 0,0 & 0,0 & 100,0 & 0,0 & 0,0 \\
\hline & 4. SEBRAE & 33,3 & 33,3 & 33,3 & 0,0 & 41,7 & 58,3 & 25,0 & 0,0 & 75,0 & 0,0 & 50,0 & 50,0 \\
\hline & $\begin{array}{l}\text { 5. Outras } \\
\text { Instituições }\end{array}$ & 33,3 & 66,7 & 0,0 & 33,3 & 66,7 & 0,0 & 37,5 & 62,5 & 0,0 & 0,0 & 50,0 & 50,0 \\
\hline \multirow{5}{*}{ 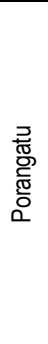 } & $\begin{array}{l}\text { 1. Governo } \\
\text { Federal }\end{array}$ & 11,1 & 77,8 & 11,1 & 13,3 & 46,7 & 40,0 & 11,1 & 33,3 & 55,6 & 0,0 & 0,0 & 100,0 \\
\hline & $\begin{array}{l}\text { 2. Governo } \\
\text { Estadual }\end{array}$ & 22,2 & 33,3 & 44,4 & 20,0 & 13,3 & 66,7 & 0,0 & 55,6 & 44,4 & 0,0 & 0,0 & 100,0 \\
\hline & $\begin{array}{l}\text { 3. Goevrno Local } \\
\text { Municipal }\end{array}$ & 100,0 & 0,0 & 0,0 & 100,0 & 0,0 & 0,0 & 100,0 & 0,0 & 0,0 & 100,0 & 0,0 & 0,0 \\
\hline & 4. SEBRAE & 11,1 & 22,2 & 66,7 & 6,7 & 40,0 & 53,3 & 11,1 & 22,2 & 66,7 & 0,0 & 50,0 & 50,0 \\
\hline & $\begin{array}{l}\text { 5. Outras } \\
\text { Instituições }\end{array}$ & 44,4 & 55,6 & 0,0 & 53,3 & 46,7 & 0,0 & 22,2 & 77,8 & 0,0 & 0,0 & 0,0 & 100,0 \\
\hline
\end{tabular}

Fonte: Pesquisa de campo 
Fica evidente a atuação do Estado no APL de Cerâmica Vermelha do Norte Goiano, tendo em vista a resposta dada pelos gestores, pois verifica-se que mais de $40 \%$ das micro e médias empresas, mais de $60 \%$ da pequenas e 100\% das grandes empresas conhecem e participam das políticas estaduais voltadas para o setor, embora haja um percentual que alega conhecer a não participar. Foi questionado aos gestores o motivo deles alegarem conhecer e não participar, haja vista que existe um PDP do APL com intuito de promover e desenvolver o arranjo e implementar as ações em parceria com outras instituições. De acordo com a maioria dos que afirmaram conhecer e não participar, informaram que participaram das reuniões para formalização do APL, do desenvolvimento do PDP, entretanto, em virtude da distância, eles (gestores) não conseguem se envolver em outras atividades. Esses gestores justificaram ainda, que a maioria das ações tem contemplado as médias e grandes empresas. Essa afirmação é uma forma de os respondentes de demostrarem o descontentamento com algumas ações realizadas no APL que, em dado momento, não abarcaram e não beneficiaram a todas as empresas, como o caso do financiamento, com recursos do FUNMINERAL, disponibilizado para apenas duas empresas do APL.

Já o caso do APL de Itabaianinha diferencia-se da situação do APL de Goiás justamente em virtude de a política de apoio a arranjos ter surgido de uma estratégia explícita do governo estadual. A SEDETEC-SE com apoio de instituições de pesquisa e de ensino, tem realizado ações que objetivam desenvolver o APL Cerâmico, bem como outros APLs localizados no estado de Sergipe. Verifica-se que a maioria das empresas inseridas no APL de Itabaianinha conhece e participa das ações implementadas pelo Estado, visto que somente $11 \%$ das pequenas empresas alegam não conhecer as políticas estaduais desenvolvidas para o setor.

A tabela 5 ratifica as afirmações da tabela anterior, uma vez que ela apresenta a avaliação dos gestores das empresas em relação às políticas específicas para o setor em que atuam.

Interessante mostrar que, para o APL de Monte Carmelo, embora as micro e pequenas empresas afirmem participar das ações promovidas pelo governo federal, 66,7\% delas e $25 \%$ das médias empresas avaliaram como sendo negativas as ações. Já para as grandes empresas, $100 \%$ delas alegam não ter elementos suficientes para avaliação, o que condiz com a resposta anterior, visto que esses gestores afirmaram não conhecer, ou conhecer e não participar das ações promovidas pelo governo federal. Na opinião dos gestores, o apoio do governo federal deveria vir acompanhado de incentivos financeiros, haja vista os custos de adequação para o processo de certificação. Quanto às médias empresas não houve uma resposta predominante, sendo que $37,5 \%$ consideram de forma positiva e outros $37,5 \%$ consideram não possuir elementos para avaliar.

A pesquisa de campo revelou uma discrepância no entendimento dos gestores sobre políticas públicas específicas para o setor. Verificou-se empresas que consideram as normas regulamentadoras, quais sejam, o projeto de lei para regulamentação da extração da argila e também para recuperação das áreas degradas, como sendo políticas específicas para o setor, e as avaliam de forma negativa, dado o trabalho, os custos e a morosidade do processo. Entretanto, outras empresas não tem o mesmo entendimento.

No tocante às ações promovidas pelo governo municipal, as empresas foram unânimes ao afirmarem que desconhecem políticas específicas para o setor e, portanto, consideram não possuírem elementos para avaliação. Em relação às ações promovidas pelo SEBRAE, apenas 33,7\% das micro empresas, $58 \%$ das pequenas, $75 \%$ das médias e $50 \%$ das grandes afirmam conhecer e participar. A avaliação é positiva para a maioria das empresas, exceto para as pequenas empresas, em que 50\% delas consideraram como negativa a atuação do SEBRAE no APL de Monte Carmelo. O SEBRAE desenvolveu ações específicas para capacitação de gestores das cerâmicas em parceria com a Associação dos Ceramistas.

Para os APLs de Porangatu e de Itabaianinha, pode-se afirmar que a maioria das empresas consideram positiva as ações federais e estaduais. Entretanto, verifica-se que $100 \%$ das grandes empresas do APL de Itabaianinha avaliaram negativamente as ações federais e positivamente as ações estaduais. $\mathrm{O}$ gestor da grande empresa do APL de Itabaianinha justifica que as ações federais são incipientes e que não há impacto no desenvolvimento local. 
Tabela 5. Percentual das empresas que avaliaram as políticas especificas para o setor das empresas dos APLs

\begin{tabular}{|c|c|c|c|c|c|c|c|c|c|c|c|c|c|}
\hline & \multirow[b]{2}{*}{ Instituição } & \multicolumn{3}{|c|}{ Micro } & \multicolumn{3}{|c|}{ Pequena } & \multicolumn{3}{|c|}{ Média } & \multicolumn{3}{|c|}{ Grande } \\
\hline & & $\begin{array}{l}\text { Avaliaç } \\
\text { ão } \\
\text { Positiva }\end{array}$ & $\begin{array}{c}\text { Avaliação } \\
\text { Negativa }\end{array}$ & $\begin{array}{c}\text { Sem } \\
\text { elementos } \\
\text { para } \\
\text { Avaliação }\end{array}$ & $\begin{array}{c}\text { Avaliaçã } \\
\text { o } \\
\text { Positiva }\end{array}$ & $\begin{array}{l}\text { Avaliação } \\
\text { Negativa }\end{array}$ & $\begin{array}{c}\text { Sem } \\
\text { elemento } \\
\text { s para } \\
\text { Avaliaçã } \\
\text { o }\end{array}$ & $\begin{array}{c}\text { Avaliaçã } \\
\text { o } \\
\text { Positiva }\end{array}$ & $\begin{array}{l}\text { Avaliação } \\
\text { Negativa }\end{array}$ & $\begin{array}{c}\text { Sem } \\
\text { elementos } \\
\text { para } \\
\text { Avaliação }\end{array}$ & $\begin{array}{c}\text { Avaliaçã } \\
\text { o } \\
\text { Positiva }\end{array}$ & $\begin{array}{c}\text { Avaliação } \\
\text { Negativa }\end{array}$ & $\begin{array}{c}\text { Sem } \\
\text { elementos } \\
\text { para } \\
\text { Avaliação }\end{array}$ \\
\hline \multirow{5}{*}{ 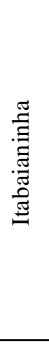 } & 1. Governo Federal & 83,3 & 0,0 & 16,7 & 58,8 & 17,6 & 23,5 & 66,7 & 0,0 & 33,3 & 0,0 & 100,0 & 0,0 \\
\hline & $\begin{array}{l}\text { 2. Governo } \\
\text { Estadual }\end{array}$ & 33,3 & 50,0 & 16,7 & 64,7 & 35,3 & 0,0 & 83,3 & 16,7 & 0,0 & 100,0 & 0,0 & 0,0 \\
\hline & $\begin{array}{l}\text { 3. Goevrno } \\
\text { Loca/Municipal }\end{array}$ & 0,0 & 0,0 & 100,0 & 0,0 & 0,0 & 100,0 & 0,0 & 0,0 & 100,0 & 0,0 & 0,0 & 100,0 \\
\hline & 4. SEBRAE & 50,0 & 0,0 & 50,0 & 47,1 & 29,4 & 23,5 & 50,0 & 50,0 & 0,0 & 0,0 & 100,0 & 0,0 \\
\hline & $\begin{array}{l}\text { 5. Outras } \\
\text { Instituições }\end{array}$ & 66,7 & 16,7 & 16,7 & 52,9 & 17,6 & 29,4 & 83,3 & 0,0 & 16,7 & 100,0 & 0,0 & 0,0 \\
\hline \multirow{5}{*}{ 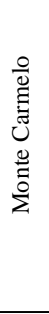 } & 1. Governo Federal & 33,3 & 66,7 & 0,0 & 25,0 & 66,7 & 8,3 & 37,5 & 25,0 & 37,5 & 0,0 & 0,0 & 100,0 \\
\hline & $\begin{array}{l}\text { 2. Governo } \\
\text { Estadual }\end{array}$ & 0,0 & 0,0 & 100,0 & 0,0 & 0,0 & 100,0 & 0,0 & 0,0 & 100,0 & 0,0 & 0,0 & 100,0 \\
\hline & $\begin{array}{l}\text { 3. Goevrno } \\
\text { Loca/Municipal }\end{array}$ & 0,0 & 0,0 & 100,0 & 0,0 & 0,0 & 100,0 & 0,0 & 0,0 & 100,0 & 0,0 & 0,0 & 100,0 \\
\hline & 4. SEBRAE & 83,3 & 16,7 & 0,0 & 41,7 & 50,0 & 8,3 & 62,5 & 12,5 & 25,0 & 50,0 & 50,0 & 0,0 \\
\hline & $\begin{array}{l}\text { 5. Outras } \\
\text { Instituições }\end{array}$ & 50,0 & 33,3 & 16,7 & 75,0 & 8,3 & 16,7 & 62,5 & 12,5 & 25,0 & 100,0 & 0,0 & 0,0 \\
\hline \multirow{5}{*}{ 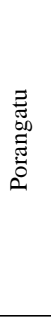 } & 1. Governo Federal & 66,7 & 11,1 & 22,2 & 46,7 & 20,0 & 33,3 & 88,9 & 11,1 & 0,0 & 100,0 & 0,0 & 0,0 \\
\hline & $\begin{array}{l}\text { 2. Governo } \\
\text { Estadual }\end{array}$ & 44,4 & 55,6 & 0,0 & 60,0 & 26,7 & 13,3 & 66,7 & 33,3 & 0,0 & 100,0 & 0,0 & 0,0 \\
\hline & $\begin{array}{l}\text { 3. Goevrno } \\
\text { Loca/Municipal }\end{array}$ & 0,0 & 0,0 & 100,0 & 0,0 & 0,0 & 100,0 & 0,0 & 0,0 & 100,0 & 0,0 & 0,0 & 100,0 \\
\hline & 4. SEBRAE & 55,6 & 22,2 & 22,2 & 66,7 & 26,7 & 6,7 & 33,3 & 22,2 & 44,4 & 0,0 & 100,0 & 0,0 \\
\hline & $\begin{array}{l}\text { 5. Outras } \\
\text { Instituições }\end{array}$ & 33,3 & 11,1 & 55,6 & 60,0 & 6,7 & 33,3 & 55,6 & 22,2 & 22,2 & 100,0 & 0,0 & 0,0 \\
\hline
\end{tabular}

Fonte: Pesquisa de campo

As ações realizadas pela SEBRAE são consideradas positivas para a maioria das empresas localizadas nos três APLs em questão, exceto para as grandes empresas do APL de Itabaianinha e do APL de Porangatu. Os gestores alegam que ações promovidas pelo SEBRAE são direcionadas às MPEs e, em casos de cursos e treinamentos ofertados,, as empresas de grande porte não são contempladas.

Outras informações levantadas na pesquisa de campo contemplaram a identificação das políticas voltadas aos APLs para criação, consolidação e/ou aperfeiçoamento dos elementos. Os dados foram tabulados por grupo do tipo de ação desenvolvida, considerando 11 grupos, quais sejam: acesso a informação; acesso a insumos; acesso a mercados e demanda; governança; capacitação; inovação e qualidade; administração e gerenciamento; infraestrutura física; financiamento; incentivos e meio ambiente. É possível identificar nas tabelas 6, 7 e 8 a percepção dos gestores por porte de empresa e por tipo de ação desenvolvida, para os APLs de Monte Carmelo, Porangatu e Itabaianinha, respectivamente.

A tabela 6 apresenta o resultado da pesquisa para o APL de Monte Carmelo. Algumas informações são relevantes, como o acesso à informação de mercado, que é de conhecimento de $100 \%$ das micro e grandes empresas; de $91,7 \%$ das pequenas e $75 \%$ das médias empresas do APL, apresentando índice de avaliação de êxito na ação de mais de 50\%. Outro dado que merece destaque refere-se à capacitação. As empresas são unânimes ao dizer que conhecem a ação, entretanto, o índice de avaliação de êxito da ação é inferior a 50\%, exceto para as grandes empresas. Administração e gerenciamento é o terceiro grupo a ser destacado, uma vez que todas as empresas afirmam conhecer essa ação, tendo esse grupo apresentado índice de avaliação de êxito de mais de 69\%, embora ainda apresente índice 1 para a importância da necessidade de outras ações do gênero. 
Por fim, outro grupo de ação que se faz relevante comentar diz respeito àquelas relacionadas ao meio ambiente. A totalidade das empresas afirmou conhecer a ação destinada ao cumprimento desse objetivo, e mais de $79 \%$ das empresas consideraram que houve resultado efetivo, ainda que reconheçam a necessidade da realização de outras ações neste mesmo sentido. De forma negativa, identifica-se, as ações referentes a dois grupos de ações: incentivos e financiamento. As empresas afirmam não conhecer nenhuma e julgam como importante a efetivação de ações com essa temática.

O APL de Porangatu apresenta algumas informações distintas ao do APL de Monte Carmelo. Pode-se verificar, na tabela 7 , que as ações relativas ao grupo de governança são de conhecimento de todas as empresas, principalmente, no tocando aos conselhos gestores, sendo essa uma ação considerada exitosa por mais de $40 \%$ delas, sendo, em virtude desse índice, identificada a necessidade de novas ações de aperfeiçoamento da governança do APL. Os gestores afirmam que poderia haver ações de incentivo fiscal e à inovação, permitindo mais facilidade de acesso a crédito e financiamento para modernização das máquinas e equipamentos. O item de capacitação, especificamente, o de capacitação técnica, é de conhecimento de todas as empresas, ainda que não se apresente com índice de êxito. Isto se justifica pelo curso de técnico em cerâmica oferecido pelo IFG-Uruaçu, requisitado pelo APL de Porangatu, que, pelas várias razões já apresentadas, não obteve êxito. Logo, é uma ação conhecida, considerada importante, embora não tenha obtido sucesso desejado.

Uma informação que merece destaque, pelo fato de apresentar uma contradição nos dados da pesquisa de campo, refere-se ao item de financiamento. Apenas 33,3\% das micro e $6,7 \%$ das pequenas empresas alegam conhecer alguma ação específica de financiamento. Isso se contrapõe aos dados já relatados (pesquisa de campo), uma vez que os projetos do APL de Porangatu são subsidiados pela SECTEC e pelo FUNMINERAL, tendo sido disponibilizado a importância de $\mathrm{R} \$ 1,5$ milhões para aquisição de máquinas e equipamentos. Outra contradição quanto a essa informação pode ser verificada no planejamento estratégico prospectivo. Verificou-se no nesse planejamento um orçamento, conforme quadro 8, da ordem de $\mathrm{R} \$ 935.459,28$ a ser disponibilizado para o APL de Porangatu. Além disso, a pesquisa de campo, durante a entrevista com a ASCENO, identificou-se outros montantes já disponibilizados ao arranjo, quais sejam:

- 207 mil, disponibilizados pelo CNPQ, por meio de edital, destinado a desenvolvimento de novo produto (composição de matéria-prima e design da telha);

- 270 mil, disponibilizados pela SECTEC, destinado a construção do laboratório de ensaios, a ser localizado em Porangatu;

- 200 mil, disponibilizados pela prefeitura de Porangatu para a construção do referido laboratório de ensaios;

- 300 mil, disponibilizados pelo MME e pelo MDIC, utilizados para formalização das empresas do arranjo;

- Montante não informado, disponibilizado pela SECTEC, destinado à capacitação de pessoal, infraestrutura e logística.

O que ficou evidente na oportunidade das entrevistas realizadas nas empresas foi uma insatisfação com a distribuição desses recursos, e por isso alegam não conhecer as ações de financiamento. Assim como em Monte Carmelo, o grupo de ações relativas a incentivos também é considerado desconhecido pelas empresas, mas essas consideram importante a necessidade de haver ações nesse sentido.

De forma semelhante aos APLs já mencionados, encontra-se o APL de Itabaianinha. Verifica-se, na tabela 8, as ações referentes à governança, capacitação, administração e gerenciamento e meio ambiente. Quanto a esses quatro grupos de ações, as empresas do APL de Itabaianinha informaram ter conhecimento, assumem que as ações de meio ambiente e as de administração e gerenciamento obtiveram êxito, embora ainda careça de mais ações nesse sentido.

A percepção das empresas do APL de Itabaianinha também acompanha a dos demais APLs no que se refere às ações de financiamento e incentivo, pois os gestores afirmam não conhece-las, porém consideram como sendo ações necessárias e importantes. 
Tabela 6. Políticas Voltadas aos APLs para criação, consolidação e/ou aperfeiçoamento dos elementos- Monte Carmelo

\begin{tabular}{|c|c|c|c|c|c|c|c|c|c|c|c|c|c|}
\hline \multirow{2}{*}{ Grupos } & & \multicolumn{3}{|c|}{ Micro } & \multicolumn{3}{|c|}{ Pequena } & \multicolumn{3}{|c|}{ Média } & \multicolumn{3}{|c|}{ Grande } \\
\hline & & Conhecimento & Avaliação & Necessidade & Conhecimento & Avaliação & Necessidade & Conhecimento & Avaliação & Necessidade & Conhecimento & Avaliação & Necessidade \\
\hline \multirow{2}{*}{ Acesso a informação } & Informações produtivas e tecnológicas & $50,0 \%$ & 0,42 & 0,68 & $50,0 \%$ & 0,37 & 0,66 & $62,5 \%$ & 0,71 & 0,68 & $100,0 \%$ & 8,00 & 1,00 \\
\hline & Informações de Mercado & $100,0 \%$ & 0,52 & 0,87 & $91,7 \%$ & 0,69 & 0,75 & $75,0 \%$ & 0,54 & 0,90 & $100,0 \%$ & 8,00 & 1,00 \\
\hline Acesso a insumos & Central de compras & $0,0 \%$ & 0,15 & 0,70 & $0,0 \%$ & 0,10 & 0,78 & $0,0 \%$ & 0,11 & 0,58 & $0,0 \%$ & 0,00 & 1,00 \\
\hline \multirow{4}{*}{$\begin{array}{l}\text { Acesso a mercados e } \\
\text { Demanda }\end{array}$} & Redes de distribuição & $0,0 \%$ & 0,05 & 0,87 & $0,0 \%$ & 0,13 & 0,78 & $0,0 \%$ & 0,15 & 0,85 & $0,0 \%$ & 0,15 & 0,60 \\
\hline & Serviços de transporte e logística & $33,3 \%$ & 0,10 & 0,80 & $50,0 \%$ & 0,10 & 0,81 & $37,5 \%$ & 0,00 & 0,76 & $100,0 \%$ & 0,15 & 1,00 \\
\hline & $\begin{array}{l}\text { Presença on-line - divulgação, vendas, } \\
\text { etc. }\end{array}$ & $0,0 \%$ & 0,10 & 0,68 & $16,7 \%$ & 0,27 & 0,76 & $50,0 \%$ & 0,54 & 0,85 & $100,0 \%$ & 1,00 & 1,00 \\
\hline & Compras públicas & $16,7 \%$ & 0,05 & 0,75 & $25,0 \%$ & 0,15 & 0,70 & $50,0 \%$ & 0,19 & 0,90 & $100,0 \%$ & 0,60 & 1,00 \\
\hline \multirow{2}{*}{ Governança } & Conselhos gestores & $100,0 \%$ & 0,30 & 1,00 & $100,0 \%$ & 0,53 & 1,00 & $50,0 \%$ & 0,26 & 1,00 & $100,0 \%$ & 0,15 & 1,00 \\
\hline & Outras formas de governança & $50,0 \%$ & 0,00 & 1,00 & $75,0 \%$ & 0,00 & 1,00 & $100,0 \%$ & 0,00 & 1,00 & $100,0 \%$ & 0,00 & 1,00 \\
\hline \multirow{3}{*}{ Capacitação } & Superior (universidades e faculdades) & $100,0 \%$ & 0,37 & 1,00 & $100,0 \%$ & 0,21 & 1,00 & $100,0 \%$ & 0,28 & 1,00 & $0,0 \%$ & 0,00 & 1,00 \\
\hline & Capacitação Técnica & $33,3 \%$ & 0,25 & 1,00 & $33,3 \%$ & 0,20 & 1,00 & $37,5 \%$ & 0,26 & 1,00 & $80,0 \%$ & 1,00 & 1,00 \\
\hline & Capacitação Gerencial & $33,3 \%$ & 0,20 & 1,00 & $66,7 \%$ & 0,43 & 1,00 & $62,5 \%$ & 0,63 & 1,00 & $50,0 \%$ & 0,30 & 1,00 \\
\hline \multirow{4}{*}{ Inovação e qualidade } & $\begin{array}{l}\text { Laboratórios de testes, ensaios e } \\
\text { certificação }\end{array}$ & $100,0 \%$ & 0,87 & 0,75 & $0,0 \%$ & 0,95 & 0,88 & $100,0 \%$ & 0,85 & 0,66 & $100,0 \%$ & 1,00 & 0,30 \\
\hline & $\begin{array}{l}\text { Laboratórios para Pesquisa e } \\
\text { desenvolvimento }\end{array}$ & $16,7 \%$ & 0,10 & 1,00 & $0,0 \%$ & 0,13 & 1,00 & $25,0 \%$ & 0,11 & 1,00 & $0,0 \%$ & 0,15 & 1,00 \\
\hline & Serviços de Engenharia & $33,3 \%$ & 0,20 & 1,00 & $16,7 \%$ & 0,05 & 1,00 & $25,0 \%$ & 0,15 & 1,00 & $50,0 \%$ & 0,30 & 1,00 \\
\hline & Consultoria Técnica & $50,0 \%$ & 0,00 & 1,00 & $41,7 \%$ & 0,00 & 1,00 & $62,5 \%$ & 0,00 & 1,00 & $50,0 \%$ & 0,00 & 1,00 \\
\hline \multirow{3}{*}{$\begin{array}{l}\text { Administração e } \\
\text { gerenciamento }\end{array}$} & Consultorias administração & $100,0 \%$ & 0,80 & 1,00 & $100,0 \%$ & 0,80 & 1,00 & $100,0 \%$ & 0,80 & 1,00 & $100,0 \%$ & 0,80 & 1,00 \\
\hline & Contabilidade & $100,0 \%$ & 0,45 & 1,00 & $91,7 \%$ & 0,63 & 1,00 & $100,0 \%$ & 0,45 & 1,00 & $100,0 \%$ & 0,30 & 1,00 \\
\hline & Marketing & $50,0 \%$ & 0,20 & 1,00 & $58,3 \%$ & 0,39 & 1,00 & $75,0 \%$ & 0,43 & 1,00 & $50,0 \%$ & 0,30 & 1,00 \\
\hline \multirow{4}{*}{$\begin{array}{l}\text { Infra-estrutura física } \\
\text { (Logística) }\end{array}$} & Área para instalação & $0,0 \%$ & 0,00 & 1,00 & $0,0 \%$ & 0,00 & 1,00 & $0,0 \%$ & 0,00 & 1,00 & $0,0 \%$ & 0,00 & 1,00 \\
\hline & Transportes & $33,3 \%$ & 0,10 & 0,80 & $50,0 \%$ & 0,10 & 0,81 & $37,5 \%$ & 0,00 & 0,76 & $100,0 \%$ & 0,15 & 1,00 \\
\hline & Telecomunicações & $100,0 \%$ & 0,63 & 1,00 & $83,3 \%$ & 0,50 & 1,00 & $100,0 \%$ & 0,61 & 1,00 & $100,0 \%$ & 0,80 & 1,00 \\
\hline & Energia, etc & $100,0 \%$ & 0,75 & 0,63 & $100,0 \%$ & 0,80 & 0,63 & $100,0 \%$ & 0,38 & 0,58 & $100,0 \%$ & 0,60 & 0,80 \\
\hline \multirow{3}{*}{$\begin{array}{c}\text { Financiamento } \\
\text { (inovação, giro e } \\
\text { capital) }\end{array}$} & Bancos (quais produtos?) & $16,7 \%$ & 0,25 & 0,52 & $16,7 \%$ & 0,28 & 0,90 & $12,5 \%$ & 0,19 & 0,95 & $0,0 \%$ & 0,00 & 1,00 \\
\hline & Outras instituições & $0,0 \%$ & 0,00 & 0,00 & $0,0 \%$ & 0,00 & 0,00 & $0,0 \%$ & 0,00 & 0,00 & $0,0 \%$ & 0,00 & 0,00 \\
\hline & Certificado de "confiança do APL" & $0,0 \%$ & 0,00 & 0,00 & $0,0 \%$ & 0,00 & 0,00 & $0,0 \%$ & 0,00 & 0,00 & $0,0 \%$ & 0,00 & 0,00 \\
\hline \multirow[b]{2}{*}{ Incentivos } & Incentivos fiscais & $0,0 \%$ & 0,00 & 1,00 & $0,0 \%$ & 0,00 & 1,00 & $0,0 \%$ & 0,00 & 1,00 & $0,0 \%$ & 0,00 & 1,00 \\
\hline & $\begin{array}{l}\text { Estímulo ao investimento (venture } \\
\text { capital) }\end{array}$ & $0,0 \%$ & 0,00 & 1,00 & $0,0 \%$ & 0,00 & 1,00 & $0,0 \%$ & 0,00 & 1,00 & $0,0 \%$ & 0,00 & 1,00 \\
\hline \multirow[b]{2}{*}{ Meio Ambiente } & $\begin{array}{l}\text { Tratamento de efluentes, resíduos } \\
\text { sólidos e/ou emissões atmosféricas }\end{array}$ & $100,0 \%$ & 0,93 & 0,73 & $100,0 \%$ & 0,87 & 0,90 & $100,0 \%$ & 0,70 & 0,85 & $100,0 \%$ & 0,80 & 1,00 \\
\hline & $\begin{array}{l}\text { Ecoeficiência( redução de } \\
\text { desperdícios, eficiência energética, etc) }\end{array}$ & $50,0 \%$ & 0,43 & 1,00 & $58,3 \%$ & 0,71 & 1,00 & $75,0 \%$ & 0,66 & 1,00 & $50,0 \%$ & 0,45 & 1,00 \\
\hline
\end{tabular}

Fonte: Pesquisa de campo 
Tabela 7. Políticas Voltadas aos APL para criação, consolidação e/ou aperfeiçoamento dos elementos- Porangatu

\begin{tabular}{|c|c|c|c|c|c|c|c|c|c|c|c|c|c|}
\hline \multirow{2}{*}{ Grupos } & & \multicolumn{3}{|c|}{ Micro } & \multicolumn{3}{|c|}{ Pequena } & \multicolumn{3}{|c|}{ Média } & \multicolumn{3}{|c|}{ Grande } \\
\hline & & Conhecimento & Avaliação & Necessidade & Conhecimento & Avaliação & Necessidade & Conhecimento & Avaliação & Necessidade & Conhecimento & Avaliação & Necessidade \\
\hline \multirow{2}{*}{ Acesso a informação } & Informações produtivas e tecnológicas & $77,0 \%$ & 0,64 & 0,6 & $66,7 \%$ & 0,57 & 0,79 & $55,6 \%$ & 0,51 & 0,67 & $50,0 \%$ & 0,30 & 0,80 \\
\hline & Informações de Mercado & $77,0 \%$ & 0,58 & 0,82 & $66,7 \%$ & 0,65 & 0,87 & $88,9 \%$ & 0,60 & 0,74 & $100,0 \%$ & 0,45 & 1,00 \\
\hline Acesso a insumos & Central de compras & $56,0 \%$ & 0,1 & 0,88 & $75,0 \%$ & 0,08 & 0,62 & $88,0 \%$ & 0,17 & 0,68 & $100,0 \%$ & 0,00 & 1,00 \\
\hline \multirow{4}{*}{$\begin{array}{l}\text { Acesso a mercados e } \\
\text { Demanda }\end{array}$} & Redes de distribuição & $33,0 \%$ & 0,07 & 0,83 & $80,0 \%$ & 0,12 & 0,90 & $66,7 \%$ & 0,17 & 0,82 & $50,0 \%$ & 0,15 & 1,00 \\
\hline & Serviços de transporte e logística & $33,0 \%$ & 0,07 & 0,88 & $13,3 \%$ & 0,10 & 0,83 & $44,4 \%$ & 0,10 & 0,66 & $50,0 \%$ & 0,00 & 1,00 \\
\hline & $\begin{array}{l}\text { Presença on-line - divulgação, vendas, } \\
\text { etc. }\end{array}$ & $44,0 \%$ & 0,48 & 0,83 & $33,3 \%$ & 0,47 & 0,85 & $11,1 \%$ & 0,21 & 0,70 & $100,0 \%$ & 0,80 & 1,00 \\
\hline & Compras públicas & $33,0 \%$ & 0,23 & 0,91 & $33,3 \%$ & 0,16 & 0,93 & $22,2 \%$ & 0,10 & 0,79 & $100,0 \%$ & 0,00 & 0,30 \\
\hline \multirow{2}{*}{ Governança } & Conselhos gestores & $100,0 \%$ & 0,68 & 1 & $100,0 \%$ & 0,58 & 0,95 & $100,0 \%$ & 0,41 & 1,00 & $100,0 \%$ & 0,60 & 1,00 \\
\hline & Outras formas de governança & $55,0 \%$ & 0 & 1 & $33,3 \%$ & 0,00 & 1,00 & $66,7 \%$ & 0,00 & 1,00 & $100,0 \%$ & 0,00 & 1,00 \\
\hline \multirow{3}{*}{ Capacitação } & Superior (universidades e faculdades) & $33,0 \%$ & 0,21 & 1 & $60,0 \%$ & 0,34 & 1,00 & $44,4 \%$ & 0,31 & 1,00 & $100,0 \%$ & 0,15 & 1,00 \\
\hline & Capacitação Técnica & $100,0 \%$ & 0,32 & 1 & $100,0 \%$ & 0,72 & 1,00 & $100,0 \%$ & 0,61 & 1,00 & $100,0 \%$ & 0,30 & 1,00 \\
\hline & Capacitação Gerencial & $66,0 \%$ & 0,20 & 1,00 & $46,7 \%$ & 0,31 & 1,00 & $55,6 \%$ & 0,50 & 1,00 & $100,0 \%$ & 0,45 & 1,00 \\
\hline \multirow{4}{*}{ Inovação e qualidade } & $\begin{array}{l}\text { Laboratórios de testes, ensaios e } \\
\text { certificaçãa }\end{array}$ & $44,4 \%$ & 0,87 & 0,75 & $33,3 \%$ & 0,52 & 0,80 & $22,2 \%$ & 0,46 & 0,66 & $100,0 \%$ & 0,60 & 0,45 \\
\hline & $\begin{array}{l}\text { Laboratórios para Pesquisa e } \\
\text { desenvolvimento }\end{array}$ & $0,0 \%$ & 0,10 & 1,00 & $6,7 \%$ & 0,12 & 1,00 & $22,2 \%$ & 0,17 & 1,00 & $0,0 \%$ & 0,00 & 1,00 \\
\hline & Serviços de Engenharia & $0,0 \%$ & 0,20 & 1,00 & $33,3 \%$ & 0,16 & 1,00 & $22,2 \%$ & 0,17 & 1,00 & $50,0 \%$ & 0,30 & 1,00 \\
\hline & Consultoria Técnica & $33,3 \%$ & 0,00 & 1,00 & $33,3 \%$ & 0,08 & 1,00 & $66,7 \%$ & 0,10 & 1,00 & $50,0 \%$ & 1,00 & 1,00 \\
\hline \multirow{3}{*}{$\begin{array}{l}\text { Administração e } \\
\text { gerenciamento }\end{array}$} & Consultorias administração & $100,0 \%$ & 0,80 & 1,00 & $100,0 \%$ & 0,76 & 1,00 & $100,0 \%$ & 0,87 & 1,00 & $100,0 \%$ & 0,80 & 1,00 \\
\hline & Contabilidade & $88,9 \%$ & 0,45 & 1,00 & $100,0 \%$ & 0,58 & 1,00 & $100,0 \%$ & 0,50 & 1,00 & $100,0 \%$ & 0,45 & 1,00 \\
\hline & Marketing & $33,3 \%$ & 0,20 & 1,00 & $53,3 \%$ & 0,33 & 1,00 & $44,4 \%$ & 0,24 & 1,00 & $100,0 \%$ & 1,00 & 1,00 \\
\hline \multirow{4}{*}{$\begin{array}{l}\text { Infra-estrutura física } \\
\text { (Logística) }\end{array}$} & Área para instalação & $0,0 \%$ & 0,00 & 1,00 & $0,0 \%$ & 0,00 & 1,00 & $0,0 \%$ & 0,00 & 1,00 & $0,0 \%$ & 0,00 & 1,00 \\
\hline & Transportes & $22,2 \%$ & 0,10 & 0,80 & $40,0 \%$ & 0,08 & 0,92 & $44,4 \%$ & 0,10 & 0,66 & $100,0 \%$ & 0,00 & 1,00 \\
\hline & Telecomunicações & $66,7 \%$ & 0,63 & 1,00 & $73,3 \%$ & 0,45 & 1,00 & $77,8 \%$ & 0,46 & 1,00 & $100,0 \%$ & 0,65 & 1,00 \\
\hline & Energia, etc & $100,0 \%$ & 0,75 & 0,63 & $86,7 \%$ & 0,66 & 0,72 & $100,0 \%$ & 0,58 & 0,76 & $100,0 \%$ & 1,00 & 1,00 \\
\hline \multirow{3}{*}{$\begin{array}{c}\text { Financiamento } \\
\text { (inovação, giro e } \\
\text { capital) }\end{array}$} & Bancos (quais produtos?) & $33,3 \%$ & 0,25 & 0,52 & $6,7 \%$ & 0,14 & 0,97 & $0,0 \%$ & 0,33 & 0,87 & $0,0 \%$ & 0,00 & 1,00 \\
\hline & Outras instituições & $0,0 \%$ & 0,00 & 0,00 & $0,0 \%$ & 0,00 & 0,00 & $0,0 \%$ & 0,00 & 0,00 & $0,0 \%$ & 0,00 & 0,00 \\
\hline & Certificado de "confiança do APL" & $0,0 \%$ & 0,00 & 0,00 & $0,0 \%$ & 0,00 & 0,00 & $0,0 \%$ & 0,00 & 0,00 & $0,0 \%$ & 0,00 & 0,00 \\
\hline \multirow[b]{2}{*}{ Incentivos } & Incentivos fiscais & $0,0 \%$ & 0,00 & 1,00 & $0,0 \%$ & 0,00 & 1,00 & $0,0 \%$ & 0,00 & 1,00 & $0,0 \%$ & 0,00 & 1,00 \\
\hline & $\begin{array}{l}\text { Estímulo ao investimento (venture } \\
\text { capital) }\end{array}$ & $0,0 \%$ & 0,00 & 1,00 & $0,0 \%$ & 0,00 & 1,00 & $0,0 \%$ & 0,00 & 1,00 & $0,0 \%$ & 0,00 & 1,00 \\
\hline \multirow[b]{2}{*}{ Meio Ambiente } & $\begin{array}{l}\text { Tratamento de efluentes, resíduos } \\
\text { sólidos e/ou emissões atmosféricas }\end{array}$ & $100,0 \%$ & 0,93 & 0,73 & $100,0 \%$ & 0,79 & 0,89 & $100,0 \%$ & 0,78 & 0,78 & $100,0 \%$ & 1,00 & 1,00 \\
\hline & $\begin{array}{l}\text { Ecoeficiência( redução de } \\
\text { desperdícios, eficiência energética, etc) }\end{array}$ & $66,7 \%$ & 0,43 & 1,00 & $73,3 \%$ & 0,71 & 1,00 & $66,7 \%$ & 0,69 & 1,00 & $100,0 \%$ & 0,15 & 1,00 \\
\hline
\end{tabular}

Fonte: Pesquisa de campo 
Tabela 8. Políticas Voltadas aos APL para criação, consolidação e/ou aperfeiçoamento dos elementos- Itabaianinha

\begin{tabular}{|c|c|c|c|c|c|c|c|c|c|c|c|c|c|}
\hline \multirow[b]{2}{*}{ Grupos } & \multirow{2}{*}{$\begin{array}{c}\text { Tipos de ações } \\
\text { criação, consolidação e/ou } \\
\text { aperfeiçoamento de: }\end{array}$} & \multicolumn{3}{|c|}{ Micro } & \multicolumn{3}{|c|}{ Pequena } & \multicolumn{3}{|c|}{ Média } & \multicolumn{3}{|c|}{ Grande } \\
\hline & & Conhecimento & Avaliação & Necessidade & Conhecimento & Avaliação & Necessidade & Conhecimento & Avaliação & Necessidade & Conhecimento & Avaliação & Necessidade \\
\hline \multirow{2}{*}{ Acesso a informação } & Informações produtivas e tecnológicas & $16,7 \%$ & 0,30 & 0,68 & $70,6 \%$ & 0,58 & 0,69 & $83,3 \%$ & 0,63 & 0,75 & $0,0 \%$ & 0,00 & 0,60 \\
\hline & Informações de Mercado & $83,3 \%$ & 0,58 & 0,87 & $88,2 \%$ & 0,65 & 0,88 & $83,3 \%$ & 0,50 & 0,82 & $0,0 \%$ & 1,00 & 0,30 \\
\hline Acesso a insumos & Central de compras & $0,0 \%$ & 0,15 & 0,57 & $0,0 \%$ & 0,09 & 0,72 & $0,0 \%$ & 0,10 & 0,87 & $0,0 \%$ & 0,00 & 1,00 \\
\hline \multirow{4}{*}{$\begin{array}{l}\text { Acesso a mercados e } \\
\text { Demanda }\end{array}$} & Redes de distribuição & $66,7 \%$ & 0,10 & 0,75 & $64,7 \%$ & 0,11 & 0,91 & $66,7 \%$ & 0,15 & 0,87 & $100,0 \%$ & 0,00 & 0,60 \\
\hline & Serviços de transporte e logística & $16,7 \%$ & 0,15 & 0,68 & $23,5 \%$ & 0,07 & 0,86 & $50,0 \%$ & 0,00 & 0,87 & $100,0 \%$ & 0,00 & 0,60 \\
\hline & $\begin{array}{l}\text { Presença on-line - divulgação, vendas, } \\
\text { etc. }\end{array}$ & $0,0 \%$ & 0,15 & 0,63 & $29,4 \%$ & 0,33 & 0,82 & $50,0 \%$ & 0,60 & 0,87 & $0,0 \%$ & 0,30 & 1,00 \\
\hline & Compras públicas & $33,3 \%$ & 0,10 & 0,70 & $29,4 \%$ & 0,18 & 0,82 & $50,0 \%$ & 0,20 & 0,82 & $0,0 \%$ & 0,00 & 1,00 \\
\hline \multirow{2}{*}{ Governança } & Conselhos gestores & $100,0 \%$ & 0,63 & 1,00 & $100,0 \%$ & 0,49 & 0,98 & $100,0 \%$ & 0,47 & 0,93 & $100,0 \%$ & 0,60 & 1,00 \\
\hline & Outras formas de governança & $66,7 \%$ & 0,00 & 1,00 & $52,9 \%$ & 0,00 & 1,00 & $50,0 \%$ & 0,00 & 1,00 & $100,0 \%$ & 0,00 & 1,00 \\
\hline \multirow{3}{*}{ Capacitação } & Superior (universidades e faculdades) & $16,7 \%$ & 0,43 & 1,00 & $47,1 \%$ & 0,20 & 1,00 & $100,0 \%$ & 0,25 & 1,00 & $0,0 \%$ & 0,00 & 1,00 \\
\hline & Capacitação Técnica & $100,0 \%$ & 0,53 & 1,00 & $100,0 \%$ & 0,44 & 1,00 & $100,0 \%$ & 0,65 & 1,00 & $100,0 \%$ & 1,00 & 1,00 \\
\hline & Capacitação Gerencial & $33,3 \%$ & 0,32 & 1,00 & $52,9 \%$ & 0,32 & 1,00 & $100,0 \%$ & 0,77 & 1,00 & $100,0 \%$ & 0,30 & 1,00 \\
\hline \multirow{4}{*}{ Inovação e qualidade } & $\begin{array}{l}\text { Laboratórios de testes, ensaios e } \\
\text { certificação }\end{array}$ & $16,7 \%$ & 0,53 & 0,63 & $41,2 \%$ & 0,58 & 0,74 & $33,3 \%$ & 0,53 & 0,67 & $0,0 \%$ & 0,30 & 0,60 \\
\hline & $\begin{array}{l}\text { Laboratórios para Pesquisa e } \\
\text { desenvolvimento }\end{array}$ & $33,3 \%$ & 0,10 & 1,00 & $5,9 \%$ & 0,11 & 1,00 & $0,0 \%$ & 0,10 & 1,00 & $0,0 \%$ & 0,30 & 1,00 \\
\hline & Serviços de Engenharia & $16,7 \%$ & 0,10 & 1,00 & $41,2 \%$ & 0,19 & 1,00 & $0,0 \%$ & 0,05 & 1,00 & $0,0 \%$ & 0,00 & 1,00 \\
\hline & Consultoria Técnica & $50,0 \%$ & 0,15 & 1,00 & $47,1 \%$ & 0,11 & 1,00 & $83,3 \%$ & 0,27 & 1,00 & $0,0 \%$ & 0,00 & 1,00 \\
\hline \multirow{3}{*}{$\begin{array}{l}\text { Administração e } \\
\text { gerenciamento }\end{array}$} & Consultorias administração & $100,0 \%$ & 0,80 & 1,00 & $100,0 \%$ & 0,81 & 1,00 & $100,0 \%$ & 0,73 & 1,00 & $100,0 \%$ & 0,60 & 1,00 \\
\hline & Contabilidade & $83,3 \%$ & 0,47 & 1,00 & $100,0 \%$ & 0,53 & 1,00 & $100,0 \%$ & 0,55 & 1,00 & $100,0 \%$ & 0,60 & 1,00 \\
\hline & Marketing & $66,7 \%$ & 0,43 & 1,00 & $52,9 \%$ & 0,35 & 1,00 & $50,0 \%$ & 0,32 & 1,00 & $100,0 \%$ & 0,60 & 1,00 \\
\hline \multirow{4}{*}{$\begin{array}{l}\text { Infra-estrutura física } \\
\text { (Logística) }\end{array}$} & Área para instalação & $0,0 \%$ & 0,00 & 1,00 & $0,0 \%$ & 0,00 & 1,00 & $0,0 \%$ & 0,00 & 1,00 & $0,0 \%$ & 0,00 & 1,00 \\
\hline & Transportes & $16,7 \%$ & 0,15 & 0,68 & $41,2 \%$ & 0,07 & 0,86 & $66,7 \%$ & 0,00 & 0,87 & $100,0 \%$ & 0,00 & 0,60 \\
\hline & Telecomunicações & $83,3 \%$ & 0,47 & 1,00 & $94,1 \%$ & 0,67 & 1,00 & $66,7 \%$ & 0,30 & 1,00 & $100,0 \%$ & 0,30 & 1,00 \\
\hline & Energia, etc & $100,0 \%$ & 0,72 & 0,57 & $100,0 \%$ & 0,62 & 0,67 & $83,3 \%$ & 0,47 & 0,75 & $100,0 \%$ & 1,00 & 0,30 \\
\hline \multirow{3}{*}{$\begin{array}{c}\text { Financiamento } \\
\text { (inovação, giro e } \\
\text { capital) }\end{array}$} & Bancos (quais produtos?) & $0,0 \%$ & 0,40 & 0,93 & $17,6 \%$ & 0,19 & 0,95 & $16,7 \%$ & 0,10 & 0,87 & $0,0 \%$ & 0,00 & 1,00 \\
\hline & Outras instituições & $0,0 \%$ & 0,00 & 0,00 & $0,0 \%$ & 0,00 & 0,00 & $0,0 \%$ & 0,00 & 0,00 & $0,0 \%$ & 0,00 & 0,00 \\
\hline & Certificado de "confiança do APL" & $0,0 \%$ & 0,00 & 0,00 & $0,0 \%$ & 0,00 & 0,00 & $0,0 \%$ & 0,00 & 0,00 & $0,0 \%$ & 0,00 & 0,00 \\
\hline \multirow[b]{2}{*}{ Incentivos } & Incentivos fiscais & $0,0 \%$ & 0,00 & 1,00 & $0,0 \%$ & 0,00 & 1,00 & $0,0 \%$ & 0,00 & 1,00 & $0,0 \%$ & 0,00 & 1,00 \\
\hline & $\begin{array}{l}\text { Estímulo ao investimento (venture } \\
\text { capital) }\end{array}$ & $0,0 \%$ & 0,00 & 1,00 & $0,0 \%$ & 0,00 & 1,00 & $0,0 \%$ & 0,00 & 1,00 & $0,0 \%$ & 0,00 & 1,00 \\
\hline \multirow[b]{2}{*}{ Meio Ambiente } & $\begin{array}{l}\text { Tratamento de efluentes, resíduos } \\
\text { sólidos e/ou emissões atmosféricas }\end{array}$ & $100,0 \%$ & 0,87 & 0,73 & $100,0 \%$ & 0,88 & 0,88 & $100,0 \%$ & 0,67 & 0,93 & $100,0 \%$ & 0,60 & 1,00 \\
\hline & $\begin{array}{l}\text { Ecoeficiência( redução de } \\
\text { desperdícios, eficiência energética, etc) }\end{array}$ & $66,7 \%$ & 0,58 & 1,00 & $64,7 \%$ & 0,63 & 1,00 & $66,7 \%$ & 0,75 & 1,00 & $0,0 \%$ & 0,60 & 1,00 \\
\hline
\end{tabular}

Fonte: Pesquisa de campo 
O quadro 6 corrobora as informações das tabelas 6,7 e 8 apresentadas anteriormente. O quadro é resultado de um esforço particular para elencar as ações implementadas nos respectivos APLs, considerando a instituição que executou a ação e qual foi a financiadora da referida ação. Buscou-se identificar as ações pelo mesmo critério de seleção das tabelas, por grupos de ações, sendo os mesmos 11 grupos: acesso a informação; acesso a insumos; acesso a mercados e demanda; governança; capacitação; inovação e qualidade; administração e gerenciamento; infraestrutura física; financiamento; incentivos e meio ambiente. Embora, já adiantemos, que nas tabelas aparecem somente os grupos que tiveram ações implementadas.

Analisando as ações para o APL de Itabaianinha, verifica-se que sete dos onze grupos de ações foram realizadas no APL. Como já mencionado anteriormente, a constituição do APL de Itabaianinha partiu de uma decisão de política de desenvolvimento do Estado de Sergipe, por meio da SEDETEC. Isso se torna nítido ao analisarmos as ações implementadas, que contemplam vários órgãos executores e distintas fontes de financiamento. Fica clara a atuação do estado de Sergipe na promoção do desenvolvimento do APL de Itabaianinha. Algumas ações foram elaboradas pensando na totalidade dos APLs de cerâmica vermelha do estado de Sergipe, visto que, além do APL de Itabaianinha ainda existem mais dois APLs.

Quanto às ações implementadas no APL de Monte Carmelo, essas contemplam seis dos onze grupos de ações de política pública. Entretanto, como se observa no quadro 6, todas as ações foram executadas, ou pelo Laboratório de Ensaios de Monte Carmelo (LEMC), ou pela Associação dos Ceramistas de Monte Carmelo (ACEMC). A ação apresentada relativa ao meio ambiente foi um guia elaborado pela FEAM, a pedido do governo do Estado de Minas Gerais e, portanto, não é uma ação exclusiva para o APL de Monte Carmelo.

O quadro 6 reforça as informações da tabela 3, quando os empresários responderam desconhecer políticas de financiamento e incentivo aos APLs de cerâmica vermelha, ou para APL de maneira geral. O fato de todas as ações até aqui implementadas terem sido custeadas pela associação dos ceramistas é uma prova disto. Quando se questiona a origem do montante para subsidiar as atividades realizadas no APL de Monte Carmelo, a ACEMC diz que faz rateio entre as empresas associadas, uma vez que todas elas serão beneficiadas com as ações.

Já para o APL de Porangatu, as informações parecem discrepantes. Esse APL, dos três analisados, recebeu o maior volume de apoio financeiro, entretanto, analisando as ações implementadas, verifica-se que ainda são incipientes e se concentram em elaboração de planejamentos estratégicos, porém, as ações elencadas nesses planejamentos ainda não estão sendo implementadas.

Analisando-se as ações implementadas nos três APLs, verifica-se que o APL de Monte Carmelo atua de forma independente, sem parceiras com instituições governamentais, não usufruindo das políticas estudais ou nacionais para promoção e desenvolvimento dos APLs.

As ações implementadas no APL de Porangatu e no APL de Itabaianinha, se analisadas conforme o documento do MDIC, giram basicamente em torno de dois eixos estruturantes: o de governança e cooperação, que buscam consolidar as relações interfirmas e a de formação e capacitação de mão de obra, influenciando diretamente na construção de capital humano.

Conforme apontado por Campos, Vargas e Satallivieri (2010), é possível analisar as políticas para APLs com base em quatro aspectos: a forma de articulação entre os diferentes órgãos; o grau de autonomia dos estados no processo de formulação da política; o grau de formalização das políticas; e o caráter contínuo ou descontínuo da política.

A articulação entre os diferentes órgãos que atuam no apoio aos APLs influencia diretamente na orientação das políticas. No Estado de Sergipe, verifica-se que existe um engajamento das várias instituições relacionadas ao desenvolvimento dos APLs. Nota-se que é política do estado de Sergipe promover o desenvolvimento da eonomia estadual por meio da promoção dos APLs. Assim, a SEDETEC faz essa articulação com os demais órgãos e instituições necessárias. Para o APL de Porangatu, a articulação entre as instituições é menor, embora a governança do APL tenha buscado promover essas parcerias. Para o APL de Monte Carmelo, a articulação se faz por meio da ACEMC. 
Quadro 5. Principais ações implementadas nos APLs

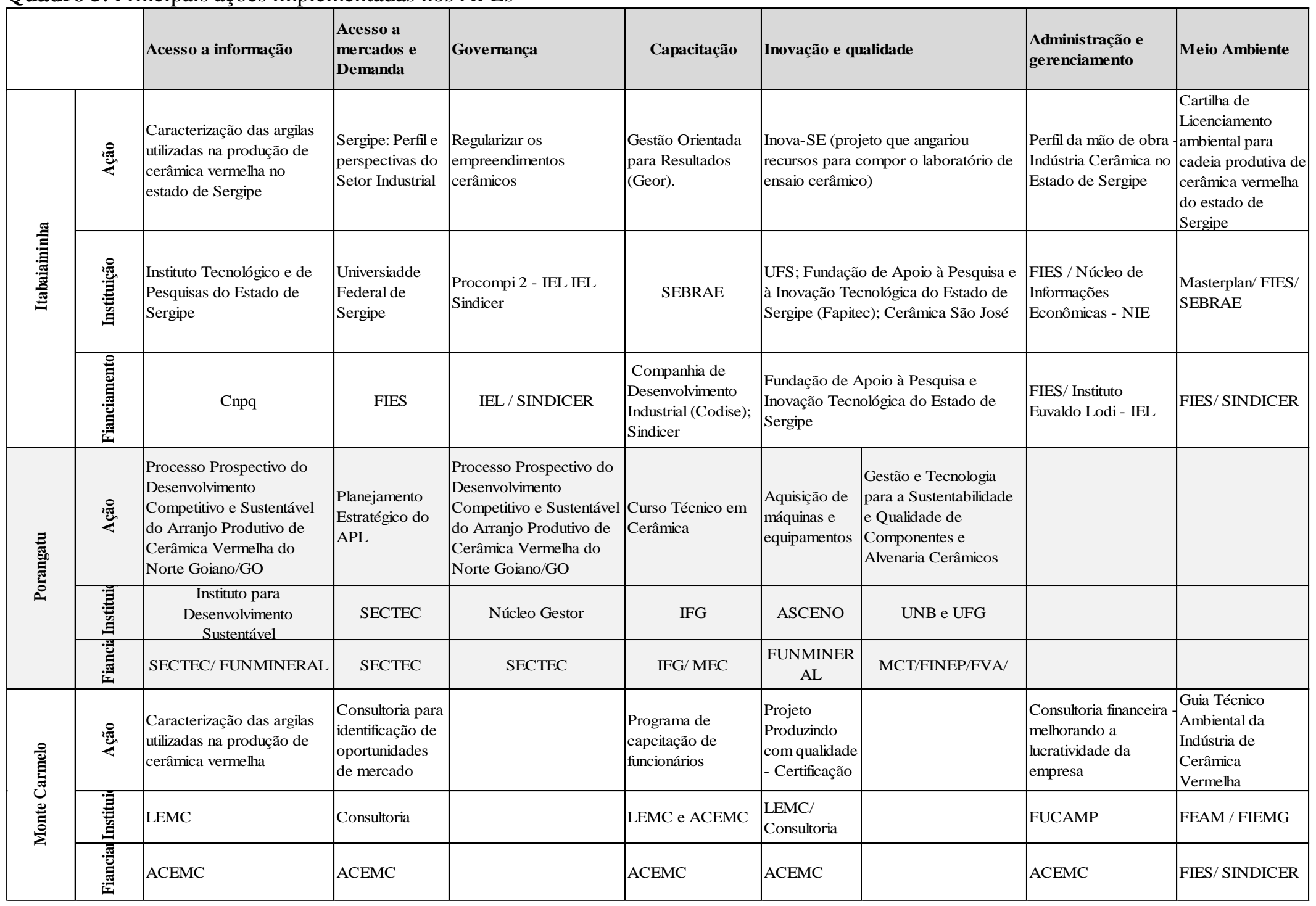


Ainda, verifica-se um alto grau de autonomia dos estados no processo de formulação e implementação de políticas, exceto pela adoção do PSQ, que é uma política nacional, as demais derivam de desdobramentos das políticas de desenvolvimento estaduais. $O$ estado de Sergipe exerce papel fundamental nas ações implementadas nos APLs, observando-se, portanto, uma continuidade das ações. O mesmo não fica evidente no caso do APL de Porangatu, onde não se verifica essa continuidade das ações.

É possível afirmar que as políticas ou ações realizadas apresentam um grau de formalização. Pode-se afirmar, também, que todas as ações aqui descritas apresentam uma formalização, seja por meio dos PDs e planejamento estratégico de cada APL, seja por meio de implementação de política pública, por meio de edital de fomento, ou ainda, com simples formalização da ação por meio de elaboração de cartilhas para disseminação de determinado conhecimento.

Outra maneira de analisar as políticas para APLs é proposta do Costa (2007), de acordo com os objetivos de política. Sob essa ótica, verifica-se que as políticas direcionadas ao APL de Itabaianinha tinham por objetivo principal fomentar o desenvolvimento local e regional, visto ser objetivo declarado pela SEDETEC, utilizando-se como instrumento o aumento da formalização das empresase o aumento da formalização da mão de obra.

O objetivo de fomentar o desenvolvimento das empresas e consequentemente do arranjo é observado nos três APLs, embora possamos afirmar que as ações realizadas no APL de Monte Carmelo cumprem mais claramente essa função. Verifica-se, na governança do arranjo, a busca por desenvolver ações que possibilitem o espraiamento das informações e o desenvolvimento das empresas. Assim, fica evidente que as ações para esse APL buscam melhorar a qualidade do produto e processo produtivo.

Um objetivo identificado no APL de Porangatu que assume destaque na análise é o de aumentar o grau de cooperação e coordenação das atividades dos agentes do arranjo. A governança do arranjo forneceu essa informação durante a pesquisa de campo. Segundo o presidente da ASCENO, como o território do APL é grande e disperso, faz-se necessário realizar ações para conscientização dos empresários quanto à importância do arranjo e da sua participação nas ações propostas no planejamento estratégico, as quais estão relacionadas a aumentar a formalização das empresas e da mão de obra.

\section{Considerações Finais}

A análise desenvolvida neste trabalho, para a caracterização dos aglomerados de empresas de cerâmica estrutural localizadas em Monte Carmelo (MG), Porangatu (GO) e Itabaianinha (SE), considerou os fatores que podem determinar a dinâmica da política pública que podem proporcionar a evolução do aglomerado em direção a sua consolidação como arranjo produtivo. Os pontos analisados partem da importância de que existem espaços para aprendizagem, para geração de economias externas, fruto da ação coletiva planejada dos atores locais, que possam proporcionar vantagens às empresas do aglomerado, e da caracterização da estrutura de governança que prevalecem, como elementos fundamentais para a evolução dos aglomerados em direção a sua consolidação.

Verificou-se, com a pesquisa de campo, que os três APLs analisados são constituídos basicamente por MPEs, de setor tradicional e de baixa tecnologia. A localização das cerâmicas é determinada por dois fatores principais: a proximidade de jazidas (em função do volume de matéria-prima processada e da necessidade de transporte de grande volume e peso) e a proximidade dos mercados consumidores (tendo em vista os custos de transporte), visto que, quanto maior o grau de qualidade da argila, maior é a importância assumida por esse fator locacional. A localização de uma empresa longe do local de extração da argila, somente se justifica quando essa é de qualidade excepcional.

Embora os três APLs apresentem governança em rede, verifica-se algumas distinções entre eles, em razão dos objetivos traçados para o APL. No caso específico do APL de Monte Carmelo, há uma governança explícita e atuante, exercida pela ACEMC, que trabalha de forma a coordenar as ações para promoção e disseminação do conhecimento entre as empresas, com intuito de melhorar a produtividade e aumentar a qualidade do produto, buscando inovações. Nota-se o forte papel desempenhado pela associação dos ceramistas nas decisões gerais que envolvam o desenvolvimento de ações pertinentes a todo o arranjo, assumindo a ACEMC a função de liderança. 
Para o APL de Itabaianinha, identificou-se a forte atuação do Estado na gestão do APL, com o papel central da SEDETEC, que, diferentemente da situação apresentada em Monte Carmelo, tinha por objetivo principal, a geração de emprego e renda, e por conseguinte, o desenvolvimento do Estado, por meio da promoção do APL, bem como de outros APLs do estado de Sergipe. Logo, não foi uma atuação específica para o APL de cerâmica vermelha de Itabaianinha. Pode-se atribuir a governança, portanto, à SEDETEC, ficando as empresas e instituições de representação com papel coadjuvante. Verifica-se que a associação dos ceramistas, nesse caso, tem papel passivo nas decisões que envolvam todo o arranjo, sendo determinante nesse processo a figura da SEDETEC.

O terceiro APL investigado foi o de Porangatu. Embora exista a ASCENO, buscando exercer essa governança, ela não consegue articular as ações de forma a envolver todas as empresas, não se observando, portanto, esse papel de liderança, haja vista o resultado da pesquisa de campo, que mostra uma certa insatisfação dos empresários com relação à associação. As ações realizadas nem sempre contemplam ou envolvem todas as empresas.

Em nível institucional, verifica-se que o APL de Itabaianinha, é aquele que, dos três APLs analisados, apresenta o aparato institucional mais bem estruturado. $\mathrm{O}$ arranjo conta com o apoio ativo das instituições públicas para sua promoção, como a SEDETEC, e ainda outras instituições que se envolveram e estabeleceram parcerias para atender a demanda da SEDETEC, como o IEL - Sergipe, o SENAI, o SENAC e o SEBRAE.

O aparato institucional do APL de Monte Carmelo não conta com o apoio de instituições governamentais. Entretanto, existe um forte aparato institucional local, formado por instituições que apoiam as ações para o desenvolvimento do arranjo, sendo principalmente o laboratório de análises (LEMC) e a faculdade local (FUCAMP).

No caso do APL de Porangatu, o aparato institucional é o mais difuso. Em função de o território que compõe o arranjo ser muito extenso, e as empresas ficarem muito dispersas, a postura da maioria dos empresários do segmento está mais centrada em necessidades individuais de suas empresas do que em ações coletivas que possam contribuir para a resolução dos problemas que debilitam o arranjo. As instituições existentes, tanto as de natureza pública como as de natureza privada, embora tragam contribuições para o setor, não atuam de forma integrada e, desta forma, produzem contribuições que estão abaixo das necessidades do APL.

Por fim, esse trabalho realizou ainda a avaliação do ambiente institucional e das políticas públicas nos três casos. Verificou-se que, quanto ao APL de Monte Carmelo, embora ele esteja elencado na base de dados da Rede APLMineral, tenha sido identificado em mapeamentos e ainda apareça como APL para a ANICER, não foi identificada nenhuma ação de política pública realizada especificamente para o arranjo de Monte Carmelo.

A pesquisa de campo, principalmente, nas entrevistas realizadas com as instituições de apoio ao APL de Itabaianinha, deixou clara a importância da atuação governamental e dos órgãos pertinentes para o desenvolvimento do APL. Como dito, não somente o APL de cerâmica vermelha de Itabaianinha. Assim, todas as ações desenvolvidas no APL foram promovidas por alguma instituição parceira, relacionada às ações da SEDETEC.

Ações de política pública também foram evidenciadas no APL de Porangatu, sendo relatadas no plano de desenvolvimento do arranjo, com recursos financeiros preestabelecidos para algumas ações. Além disso, algumas empresas já foram contempladas com recursos do FUNMINERAL para a aquisição de máquinas e equipamentos. Entretanto, verificou-se, até aqui, que muitas dessas ações encontram-se somente no papel, não tendo sido implementadas. 


\section{Referências Bibliográficas}

BECATINI, G. O Distrito Marshalliano: uma noção socioeconômica". In: As regiões ganhadoras: Distritos e Redes - os novos paradigmas da geografia econômica. Oeiras: Celta Editora. 1994

BRASIL. Oficina regional de orientação à instalação de núcleos estaduais de apoio a arranjos produtivos Locais. Brasília: MDIC / GTP-APL, 2006a.

BRASIL. Manual de apoio aos arranjos produtivos Locais. Brasília: MDIC / GTP-APL, $2006 \mathrm{~b}$.

BRASIL. Ministério do Desenvolvimento, Indústria e Comércio Exterior - MDIC. Termo de referência para política nacional de apoio ao desenvolvimento de arranjos produtivos Locais. Brasília: MDIC / GTP-APL, 2004.

CAMPOS, R.R.; VARGAS, M. A.; STALLIVIERI, F. As experiências estaduais de políticas para arranjos produtivos locais. IN: CAMPOS, R.R.; STALLIVIERI, F.; VARGAS, M.A.; MATOS, M. Políticas Estaduais para Arranjos Produtivos Locais no Sul, Sudeste e Centro-Oeste do Brasil. BNDES, RedeSist, FUNPEC, 2010. Disponível em: www.politicaapls.redesist.ie.ufrj.br. Acesso em janeiro 2015.

CASSiOlato, J. E., LASTRES, H. M. M. Política para a promoção de arranjos produtivos e inovativos locais de micro e pequenas empresas: conceitos, vantagens, restrições e equívocos usuais. Rio de Janeiro: RedSist, IE/UFRJ, 2003a.

CASSIOLATO, J. E.; LASTRES, H. M. M. O foco em arranjos produtivos e inovativos locais de micro e pequenas empresas. In: LASTRES, H. M. M; CASSIOLATO, J. E.; MACIEL, M. (orgs.). Pequena empresa: cooperação e desenvolvimento local. Rio de Janeiro: Relume Dumará, 2003b.

COSTA, E. J. M. Políticas públicas e o desenvolvimento de arranjos produtivos locais em regiões periféricas. Tese de Doutoramento. Campinas, Instituto de Economia - UNICAMP, 2007.

ERBER, F. S. Eficiência coletiva em Arranjos Produtivos Locais industriais: comentando o onceito. Nova Economia, Belo Horizonte, v. 18, n. 1, p. 11-32, jan./abr. 2008.

LEMOS, C. R.. Notas preliminares do Projeto Arranjos Locais e Capacidade Inovativa em contexto Crescentemente Globalizado. IE/UFRJ, Rio de Janeiro, mimeo. 1997.

MATOS, M. P.; ARROIO, A. Políticas de apoio a micro e pequenas empresas no Brasil: Avanços no período recente e perspectivas futuras. Santiago do Chile: Comisión Económica para América Latina y el Caribe (CEPAL), 2011.

NARETTO, N.; BOTELHO, M. R.; MENDONÇA, M. A trajetória das políticas públicas para pequenas e Médias empresas no Brasil: do apoio individual ao apoio a empresas articuladas em arranjos produtivos locais. Planejamento e Políticas Públicas, n. 27, jun./dez. 2004.

TATSCH, Ana Lúcia; BOTELHO, Marisa dos R. A. Análise das políticas de apoio à arranjos produtivos locais nos estados do Centro-Sul do Brasil. Revista de Políticas Públicas. São Luís, v. 17, n. 1, p. 15-26, jan./jun. 2013.

SCHMITZ, H.; NADVI, K. Clustering and industrialization: introduction. World Development, v. 27, n. 9, Sep; 1999. 